\title{
Ion-Specific Effects in Foams
}

Soumyadip Sett ${ }^{1}$, Stoyan I. Karakashev ${ }^{2}$, Stoyan K. Smoukov ${ }^{3 *}$, Alexander L. Yarin ${ }^{1,4^{*}}$

${ }^{1}$ Department of Mechanical \& Industrial Engineering, University of Illinois, 842 West Taylor St, Chicago, IL 60607, USA.

${ }^{2}$ Department of Physical Chemistry, University of Sofia, 1164 Sofia, Bulgaria.

${ }^{3}$ Department of Materials Science and Metallurgy, University of Cambridge, 27 Charles Babbage Road, Cambridge, CB3 0FS, United Kingdom.

${ }^{4}$ College of Engineering, Korea University, Seoul, S. Korea

\section{ABSTRACT}

We present a critical review on ion-specific effects in foams in the presence of added salts. We show the theoretical basis developed for understanding experimental data in systems with ionic surfactants, as well as the nascent approaches to modelling the much more difficult systems with non-ionic surfactants, starting with the most recent models of the air-water interface. Even in the case of ionic surfactant systems, we show methods for improving the theoretical understanding and apply them forte -interpretation of surprising experimental results we have obtained on ion-specific effects in these systems.-our own. We report unexpectedly strong ion-specific effects of counter-ions on the stability and the rate of drainage of planar foam films from solutions of $0.5 \mathrm{mM}$ Sodium dodecyl sulfate (SDS) as a function of concentration of a series of inorganic salts ( $\mathrm{MCl}, \mathrm{M}=\mathrm{Li}, \mathrm{Na}, \mathrm{K})$. We found that the counter-ions can either stabilize the foam films (up to a critical concentration) or destabilize them beyond it. The ordering for destabilization is in the same order as the Hofmeister series, while for stabilization it is the reverse Therefore, the strongest foam stabilizer $\left(\mathrm{K}^{+}\right)$, becomes the strongest foam destabilizer at and beyond its critical concetration, and vice versa. Though the critical concentration is different for different salts, by-calculating the critical surfactant adsorption level one could simplify the analysis, with all the critical concentrations occuring at the same surfactant adbsorption level. Beyond this level, the foam lifetime decreases and films suddenly start draining faster, which may indicate salt-induced surfactant precipitation. Alternatively, formation of pre-micellar structures may result in slower equilibration and fewer surfactant molecules at the surface, thus leading to unstable foams and films.

Keywords: Ion-Specific Effects, Foams, Foam Films, Critical Micelle Concentration, Foam Film Drainage

*Corresponding authors: 
A.L. Yarin

Department of Mechanical and Industrial Engineering, University of Illinois at Chicago, 842 W. Taylor St., Chicago IL 60607-7022, U.S.A.

Tel: (312) 996-3472

Fax: (312) 413-0447

E-mail: ayarin@uic.edu

S. K. Smoukov

Department of Materials Science and Metallurgy,

University of Cambridge, 27 Charles, Babbage Road,

Cambridge CB3 0FS, UK.

Tel: +44 (01223) 334435

Fax: +44 (01223) 762088

E-mail: sks46@cam.ac.uk 


\section{Content}

1. Introduction

2. Ion-Specific Effects on the Adsoprtion Layers of Ionic Surfactants

3. Ion-Specific Effects on the Stability of Foams

3.1.The effect of added salts on the properties of foams and foam films stabilized by ionic surfactants.

3.2. The effect of added salts on the properties of foams and foam films stabilized by nonionic surfactants

3.3. The effects of the added salts on the properties of air/water interface

4. Novel Ion-Specific Effects on the Stability of Foams and Foam Films Stabilized by Sodium Dodecylsulfate (SDS) and added Salt

4.1. Experimental

4.2. Results and Discussion

\subsubsection{Thin Films}

4.2.2. Foam Films

5.Conclusions

6. References 


\section{INTRODUCTION}

The specific effect of the salts on the physicochemical properties of solvents, solutes, dispersed systems and biological cells were reported in series of works since the middle of $\mathrm{XIX}^{\text {-th }}$ century.-until present. Arrhenius and Kreichgauer (see e.g. Ref. [1]) reported that the different inorganic salts affect the inner friction of their aqueous solution almost identically. On the contrary, Poiseuille [2] reported that some salts increase the inner friction of their aqueous solutions, while other ones decrease the latter, athough these effects apperared to be difficult to distinguish. Ostwald [3] reported at first that the lowering of the vapor pressure of water, caused by the different salts with the same concentrations is almost the same Hhowever after careful analysis he established that the vapor pressure depends weakly on type of the added salt. Similarly, Raoult [4] reported about approximate identical lowering of the freezing point of the water caused by different salts and found out certain small differences depending on the type of the salt. Moreover, Long [5] reported that the molecular diffusion of the inorganic salts against water depends on both the inner friction of their aqueous solutions and their water absorbance. He was able to established some differences in the molecular diffusion of the salt molecules in water under identical conditions, but the results remained doubtful due to the complexity of the experiment conducted at the end of $\mathrm{XIX}^{\text {the }}$ century. Hugo de Vries [6] determined the behavior of live plant cells in different salt solutions. He reported that at certain specific concentration for each salt-concentration, the protoplasm of the cell peels away from the cell wall, leaving gaps between the cell wall and the membrane (plasmolysis). A little bitSometime later Hamburger [7] confirmed the same salt effects on red blood cells. The above-mentioned authors reported about the first cases of salt-specific effects. However, only the salt-specific effects on living cells were found to be evident.

Furthermore, the most significant and meaningful contribution in this area belongs to Hofmeister[1]. He and his team[8-14] published a whole series of seven papers entitled | "About the science of the effect of salts".-They established that the blood proteins precipitate at specific concentrations of added salts. Thus, some salts are stronger precipitators than other ones. They found out that both cations and anions of the salt contribute to this precipitation, but the effect of the anions is stronger. These old findings were confirmed nowadaysrecently by means of small angle X-ray scattering (SAXS) on interacting protein molecules[15]. Moreover, it was found out nowadays that the salt ions affect the very properties of the protein molecules in a specific way[16]. as well.Furthermore, the findings of Hofmeister and 
his team were used for building of a series of anions and cations ordered according to their precipitation ability:

Cations: $\mathrm{Li}^{+}<\mathrm{Na}^{+}<\mathrm{K}^{+}<\mathrm{Rb}^{+}<\mathrm{Cs}^{+}<\mathrm{NH}_{4}^{+}<\mathrm{NMe}_{4}^{+}$

Anions: $\mathrm{ClO}_{4}^{-}<\mathrm{BF}_{4}^{-}<\mathrm{NO}_{3}^{-}<\mathrm{Br}^{-}<\mathrm{Cl}^{-}<\mathrm{OH}^{-}<\mathrm{F}^{-}<\mathrm{CH}_{3} \mathrm{COO}^{-}$

The above mentioned series are known as Hofmeister series in the literature [17-21]. Hofmeister established the same effects of the added salts on the stability of aqueous suspension of isinglass, colloidal ferric oxide, and sodium oleate[9] as well. These discoveries unveiled a whole interdisciplinary field in the science. For example, it was recently found out that the ions affect specifically the catalytic activities of some enzymes[18], thus being important in the-medicine, pharmacy and bio-physics. Almost at the same time Setschenow established independently[22] that the organic solutes in water precipitate (salt out) at sufficient amount of added sodium chloride. He arrived at an empirical equation predicting the solubility of many non-electrolyte organic substances at different concentrations of sodium chloride. He introduced the "Setschenow's empirical constants", which are specific for every organic substance. It was established significantly much later[23] that both the anions and the cations of the salt have specific contributions to the values of "Setschenow's constants".

A few years after Hofmeister, Heydweiller[24] found out that the salt increases the surface tension of the air/water interface in surfactant free solutions. Moreover, he established that the relative effect of the ions on the surface tension follows closely the Hofmeister series, thus drawing the conclusion that the two phenomena are related. His discovery was followed by significant contributions by Langmuir[25], Wagner[26], Onsager and Samaras[27], Jones and Ray[28-32] and many other renowned scientists since the 1930s to the present[33-49]. Their studies revealed complicated interactions between the ions of the salt and the air/water (oil/water) interface resulting in the formation of spatially separated cation-depleted and anion-depleted layers at the very inter-phase boundary, thus increasing its surface tension. The parameters of these layers and the corresponding increase of the surface tension depend on the types of ions in the salt. Thus, for example, considerable efforts have been put into developing the statistical mechanical models for describing the behavior of strong electrolytes in close proximity to the interface boundary.

The Poisson-Boltzmann ( $\mathrm{PB}$ ) theory treats the ions in close proximity of charge interfaces in the classical way. It is good for predicting the behavior of univalent ions not too close to the interface for low electrolyte concentrations. Unfortunately, this theory breaks 
down at the very surface at higher surface charge densities. Consequently, further development with fewer approximations of the PB equation is needed to describe a more realistic picture. More importantly, this theory does not account for any differences between the different counter-ions, while experiments reveal clear differences in interactions at either biological or non-biological surfaces. The "counterion effect" is related to the Hofmeister series for cations or anions[50]

Bhuiyan et al. [37] described the ions from the diffusive part of the double layer as hydrated spheres in the limits of the primitive model of aqueous solutions of electrolytes, while the surface was modelled like idealized dielectric discontinuity. Furthermore, Kjellander et al. [47] introduced the pair correlation function in a form identical to the DebyeHückel theory and renormalized the charges of the ions in form of the "dressed ions" instead of the bare ion charges. According to these works, the "ion free layer" model appears to be crude. Instead, it is more probable that the ion concentration profile from the fluid interface is more complex and can even go through several abrupt oscillations before the bulk ion concentration is reached. The increment of the surface tension has been related to the hydration radius [38]. In this respect, it is important to mention the experimental work of Sakai [49], who reported the variation in the relative concentration of ions as a function of the relative distance from the bubble surface. He measured the concentration profile of $\mathrm{Mg}^{2+}$ ions from aqueous solution of $\mathrm{MgCl}_{2}$ as a function of the distance from the bubble surface. The experimental results showed that at the relative distance of 0.2 (the distance for the bulk concentration is taken to be 1) from the interface, the concentration of $\mathrm{Mg}^{2+}$ is found to be at least two times higher than the concentration in the bulk solution. At shorter distances, the concentration of $\mathrm{Mg}^{2+}$ is at least three times higher. This general picture of the concentration profiles of the ions in close proximity to the surface of the bubble was challenged in the last decade and was awarded as a highlight of the year by Science[51] some ef-years ago. Moreover, it was established that a strong salt-specific effect modifies the dynamic interaction between such bubbles. In this sense, it was found out that some salts impedes the coalescence of bubbles in surfactant free solutions above certain specific for each salt concentration, while other ones do not have such an effect[52-57]. The physical reason for these effects are still obscure despite the attempts for an explanation[53, 58-61]. Moreover, the mean activities, the osmotic coefficients[62-65] and the solubility of salts[19] in their surfactant free solutions appeared to be salt-specific as well.

In this work we report certain ion-specific effects on the stability of foams, not explained by previous theories. Our review gives the context of the previous experiments and 
theoretical treatments, including both ionic and nonionic surfactants. We touch on the relevance of ion-specific salt effects on the stability of emulsions, stabilized by ionic surfactants. In this context, we discuss our new unexpected findings of critical concentrations of added salts which cause destabilization of_sodium dodecyl sulfate (SDS) foams. We present a theoretical framework in which the otherwise arbitrary concentrations coincide with a single surfactant adbsorption level, which could be the basis for guiding further studies.

\section{ION-SPECIFIC EFFECTS ON THE ADSOPRTION LAYERS OF IONIC - SURFACTANTS}

In a historical sense, in one of the first systematic studies, Heydweiller, Adam and Shute[66] observed that in the presence of ionic surfactants, the addition of salt decreases the surface tension of the air/water interface. In this regime charge screening between neighboring ionic surfactant molecules results in a denser surfactant layer, slower draining films due to reduced surface mobility, increased Marangoni flows and more stable foams. This effect was followed later by Pethica[67], Matijevic and Rogers[68], van Voorst Vader[69] and other prominent scientists[70-79]. Their studies clearly showed that the relative decrease of the surface tension of air/water (or oil/water) interface depends mainly on the added counter-ion of the surfactant. This stabilization has the reverse order of the

Hofmeister series. This is due to the fact that the concentration of the added counter-ions in the form of salt exceed significantly the concentration of the ionic surfactant. Ionic surfactants in 1:1 ratio with different counter-ions also exhibit relative stabilities in order reverse to that of the Hofmeister series[80].

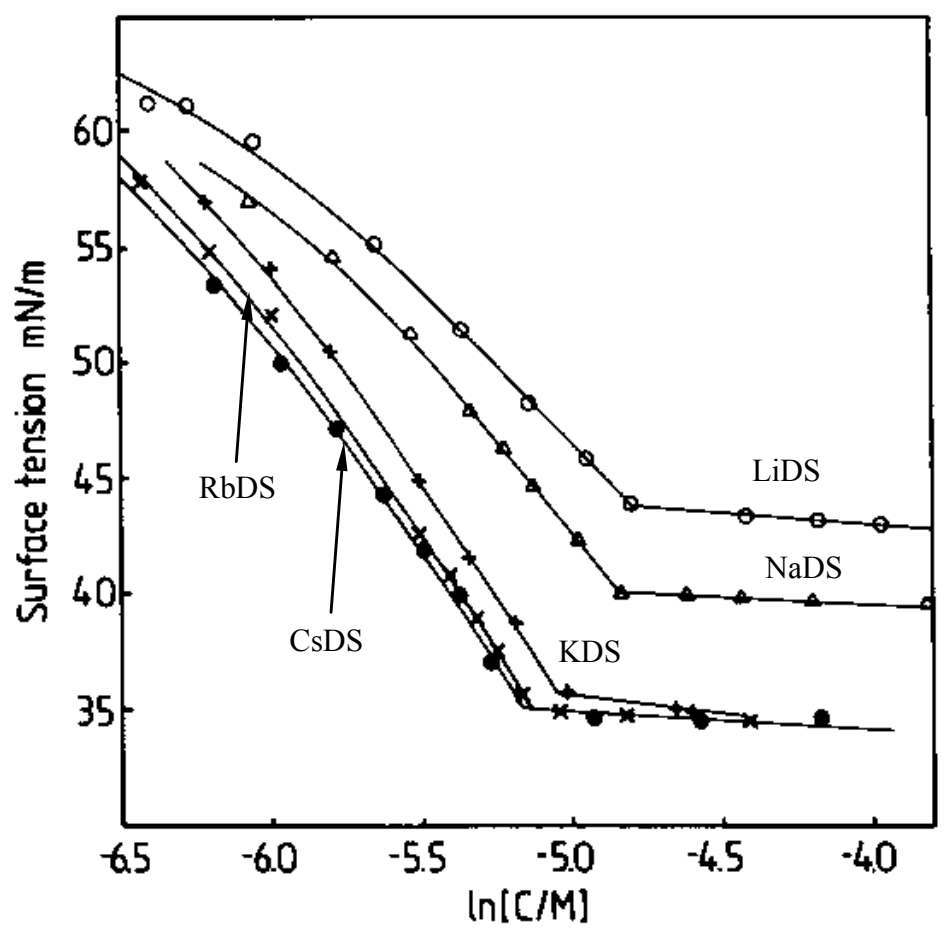


Figure 1. Surface tension versus ln (concentration) for LiDS, NaDS, KDS, RbDS and CsDS; Reprinted with the permission from Elsevier, Lu, J.R., Marrocco, A., Su, T.J., Thomas R.K., and Penfold J., "Adsoprtion of Dodecylsulfate Surfactants, with Monovalent Metal Counter-Ions at the Air-Water Interface Studied by Neutron Reflection and Surface Tension”, J. Colloid Interface Sci., $1993,158,303-316[80]$.

The equilibrium adsorption layers of ionic surfactants in the presence or absence of added salts were widely investigated in the literature (e.g. $[46,70,77,81-83])$, however the ionic surfactant was usually investigated only as a pair of a surface-active ion and its counterion. The individual contribution of the type of the counter-ions to the equilibrium adsorption constants of the ionic surfactant were not considered in many of the works. Fortunately, there was recent progress in the literature in this direction. According to the latest achievements $[21,79,84-86]$ the counter-ions penetrate into the surfactant adsorption layer, thus affecting its state and the related surface potential. The level of this penetration is quantified by the specific energy of counter-ion adsorption on the air/water interface, which can be calculated by taking into account the parameters of the counter-ion - size, polarizability, ionization potential, deformability of its hydration shell, etc. The specific energy $\mathrm{u}_{\mathrm{i} 0}$ of adsorption of the hydrated counter-ion " $i$ " in a mixture of ions on the air / water interface can be expressed by the following equations (see the supplementary material):

$$
\begin{aligned}
& u_{i 0}=\left(1-\frac{3}{4} \frac{R_{\mathrm{b}}}{R_{\mathrm{h}}}\right) \frac{2 \pi}{3} \frac{\rho_{\mathrm{w}}}{R_{\mathrm{h}}^{3}}\left(L_{i \mathrm{w}}-L_{\mathrm{ww}}\right) \\
& u_{i 0}=\frac{\pi}{6} \frac{\rho_{\mathrm{w}}}{R_{\mathrm{h}}^{3}}\left(L_{i \mathrm{w}}-L_{\mathrm{ww}}\right)
\end{aligned}
$$

where Eq. (1) is valid for ions with a deformable hydration shell (see Table 1 in the supplementary material), while Eq. (2) is valid for high charge density ions with an undeformable hydration shell $\left(\mathrm{Li}^{+}, \mathrm{Na}^{+}, \mathrm{F}^{-}, \mathrm{HO}^{-}, \mathrm{Ac}^{-}\right), R_{\mathrm{b}}$ and $R_{\mathrm{h}}$ are the radii of the bare and the hydrated ion, $\rho_{\mathrm{w}}$ is the density of the water, and $L_{i \mathrm{w}}$ and $L_{\mathrm{ww}}$ are the London constant of interaction of ion-water and water-water species, which can be presented by the following expressions: 


$$
L_{i \mathrm{w}}=\frac{3 \alpha_{\mathrm{p}, i} \alpha_{\mathrm{p}, \mathrm{w}}}{2} \frac{I_{i} I_{\mathrm{w}}}{I_{i}+I_{\mathrm{w}}} ; L_{\mathrm{ww}}=\frac{3}{4} N_{\mathrm{w}} \alpha_{\mathrm{p}, \mathrm{w}}^{2} I_{\mathrm{w}}
$$

where $\alpha_{\mathrm{p}, i}$ and $\alpha_{\mathrm{p}, \mathrm{w}}$ are the polarizabilities of ion of type "i" and the water molecule, $I_{i}$ and $I_{\mathrm{w}}$ are their ionization potentials. For the calculation of $L_{\mathrm{ww}}$, the ensemble of $N_{\mathrm{w}}$ water molecules is regarded as a sphere with polarizability $N_{w} \alpha_{\mathrm{p}, \mathrm{w}}$. The number $N_{\mathrm{w}}$ [79]was assumed equal to the ratio between the volume of the bare ion and the volume of one water molecule:

$$
N_{\mathrm{w}}=R_{\mathrm{b}}^{3} / R_{\mathrm{w}}^{3}
$$

where $R_{\mathrm{w}}$ is the effective radius of the water molecule. For the value of $R_{\mathrm{w}}$, two possibilities were tested in Ref.[79]: (i) the average volume per molecule $\left(30 \AA^{3}\right)$, based on the water density, yields $R_{\mathrm{w}}=1.93 \AA$, which averages larger distances due to hydrogen bonds and is not reflective of the van der Waals radii; and (ii) quantum-mechanical estimates of the proper volume of a water molecule, $11 \AA^{3}$, corresponds to $R_{\mathrm{w}}=1.38 \AA$ [87]. A better agreement with the experimental data was obtained with the second option, $R_{\mathrm{w}}=1.38 \AA$.

In the presence of surfactant molecules, rather than adsorbing on the surface by themselves, the counterions modify equilibrium adsorption constant $K_{0}$ of the ionic surfactant. The specific energy of counter-ion adsorption, $\mathrm{u}_{0}$, was recently described in Refs. $[79,88,89]$

$$
\ln K_{0}=\ln K_{0}^{0}-\frac{1}{2} \frac{u_{0}}{k_{B} T}
$$

where $K_{0}^{0}$ is the equilibrium adsorption constant of the ionic surfactant with no account for the ion-specific effect. The counter-ions in such a case are assumed as just point charges with no polarizability and ionization potential. The charge of the surface-active ion has contribution to the overall equilibrium adsorption constant as-well:

$$
K_{0}^{0}=\left(\frac{4 K_{S}}{\kappa_{0}^{2}}\right)^{\frac{1}{3}}
$$

where $K_{S}$ is the equilibrium adsorption constant of the surfactant with the same molecular structure, but with excluded charge, $\kappa_{0}=\sqrt{8 \pi e^{2} / \varepsilon \mathrm{k}_{\mathrm{b}} \mathrm{T}}, e$ is the charge of one electron (in CGS system), and $\varepsilon$ is the dielectric constant of the solution. The relation between the energy of adsorption $\mathrm{E}_{\mathrm{A}}$ of the uncharged surfactanft and its equilibrium adsorption constant $K_{S}$ can be expressed by: 


$$
\frac{\mathrm{E}_{\mathrm{A}}}{\mathrm{k}_{\mathrm{B}} \mathrm{T}}=\frac{\mathrm{E}_{\text {head }}}{\mathrm{k}_{\mathrm{B}} \mathrm{T}}+\frac{\sigma_{0} \alpha_{0}}{\mathrm{k}_{\mathrm{B}} \mathrm{T}}+\frac{\mathrm{u}_{\mathrm{CH} 2}}{\mathrm{k}_{\mathrm{B}} \mathrm{T}}\left(\mathrm{n}_{\mathrm{C}}+1\right)
$$

where $E_{\text {head }}$ is the contribution from the polar head, $\sigma_{0}$ is the surface tension of the air/water interface of the solvent (water), $\mathrm{u}_{\mathrm{CH} 2}$ is the adsorption energy contribution of a single methylene group in the surfactant tail, $\mathrm{n}_{C_{A}}$ is the number of the carbon atoms in the surfactant molecule, and $\alpha_{0}$ is the cross-sectional area of the surfactant molecule on the air/water interface. Eq.(7) contains mostly known quantities - the contribution of the displaced surface water molecules by the surfactant molecule $\left(\sigma_{0} \alpha_{0} / \mathrm{k}_{\mathrm{B}} \mathrm{T}=3.978\right)$, the contributions from the carbon atom groups of the surfactant tail $\left(\left(\mathrm{u}_{\mathrm{CH} 2} / \mathrm{k}_{\mathrm{B}} \mathrm{T}\right)\left(\mathrm{n}_{\mathrm{C}}+1\right),\left(\mathrm{u}_{\mathrm{CH} 2} / \mathrm{k}_{\mathrm{B}} \mathrm{T}\right)=0.96-1.26\right.$ depending on the nature of the head group [89, 90], and the only missing information isbeing the polar head contribution (first term on the right-hand side) [90]. Recently a method was found to quantify the contribution from the polar head as well, ref. [90] So ffinally the ions can be ordered according to their specific energy of adsorption on the air/water interface[79], and since spontaneous absorption leads to stabilization this order is also the reverse of the Hofmeister series (see eqs. (1),(2) and Table 1).

Table 1. Cations and anions with their specific energy of adsorption on air/water interface (for more information see the supplementary material).

\begin{tabular}{|c|c|c|c|}
\hline Cation & $\boldsymbol{u}_{\boldsymbol{i} \mathbf{0}} / \boldsymbol{k}_{\mathrm{B}} \boldsymbol{T}$ & Anion & $\boldsymbol{u}_{\mathbf{i}} / \boldsymbol{k}_{\mathbf{B}} \boldsymbol{T}$ \\
\hline $\mathrm{Li}^{+}$ & -0.09 & $\mathrm{Ac}^{-}$ & -0.185 \\
\hline $\mathrm{Na}^{+}$ & -0.33 & $\mathrm{OH}^{-}$ & -0.736 \\
\hline $\mathrm{NH}_{4}{ }^{+}$ & -0.61 & $\mathrm{~F}^{-}$ & -0.891 \\
\hline $\mathrm{K}^{+}$ & -0.90 & $\mathrm{Cl}^{-}$ & -1.43 \\
\hline $\mathrm{Rb}^{+}$ & -0.98 & $\mathrm{Br}^{-}$ & -2.32 \\
\hline $\mathrm{NMe}_{4}{ }^{+}$ & -1.05 & $\mathrm{NO}_{3}{ }^{-}$ & -2.83 \\
\hline $\mathrm{N} / \mathrm{A}$ & N/A & $\mathrm{N}_{3}{ }^{-}$ & -2.93 \\
\hline N/A & N/A & $\mathrm{ClO}_{4}{ }^{-}$ & -3.28 \\
\hline N/A & N/A & $\mathrm{BF}_{4}{ }^{-}$ & -3.84 \\
\hline
\end{tabular}

Formatted: Font: $12 \mathrm{pt}$

Formatted: Font: $12 \mathrm{pt}$

Formatted: Font: $12 \mathrm{pt}$

Formatted: Font: $12 \mathrm{pt}$

Formatted: Font: $12 \mathrm{pt}$

Formatted: Font: $12 \mathrm{pt}$

Formatted: Font: $12 \mathrm{pt}$

Formatted: Font: $12 \mathrm{pt}$

Formatted: Font: $12 \mathrm{pt}$

Formatted: Font: $12 \mathrm{pt}$

Formatted: Font: $12 \mathrm{pt}$ 


\section{ION-SPECIFIC EFFECTS ON THE STABILITY OF FOAMS}

There are a number of investigations on the effect of different added salts on the stability of foams, emulsions and thin liquid films in the literature, but unfortunately they are mostly empirical and lack-of any satisfactory theoretical interpretation, despite the fact that the DLVO theory should work in theseis particular cases We will outline some of the basic achievements in this direction.

We start by applying our knowledge of counter-ion absorption on interfaces and how it affects the electro-static repulsion between bubbles as a first attempt to predict foam stability. Every surfactant solution can be characterized by its foamability (initial foam volume upon the very generation of the foam) and lifetime of the foam[91-94]. There are number of factors, which affect the foamability and/or the foam lifetime, as-for example the type of the surfactant and its concentration[95], the air's humidity[92, 96], the presence of particles[97-99] , etc. Moreover the foams can be classified as tenacious (with long lifetime) orand transient (short-lived). The behavior changes abruptly at a critical concentration $\mathrm{c}_{\text {black }}<$ $\mathrm{c}_{\mathrm{CMC}}$, related to the formation of the so-called black foam films[100], which are very durable. Moreover, the foam stability is related to the level of surfactant adsorption on the bubbles' surfaces[92, 101, 102] and explained by their higher elastic moduli[103]. Foamability can be correlated with the diffusion coefficients of the counter-ions in the aqueous solution, and if it is fast compared to the procedure of foam generation, a higher volume foam forms [104]..

\subsection{The effect of added salts on the properties of foams and foam \\ films stabilized by ionic surfactants.} Formatted: Indent: First line: $0^{\prime \prime}$

Pandey et al. [105] eondueted original investigation aboutinvestigated the effect of the counter-ions on the foamability and foam durability of foams, stabilized by Lithium Dodecylsulfate (LiDS), Sodium Dodecylsulfate (SDS), Cesium Dodecylsulfate (CsDS) and Magnesium Dodecylsulfate $\left(\operatorname{Mg}(\mathrm{DS})_{2}\right)$. Their study was_limited to the case of a single ionic surfactant and considered relative stabilities, without the effects of other added 
salts/counterions. One can see in Fig. 2A that at $1 \mathrm{mM}$ surfactant concentration the foam stability increases in the order LiDS, SDS, CsDS, $\operatorname{Mg}(\mathrm{DS})_{2}$, which coinsides with the Hofmeister series in reverse order (excluding $\operatorname{Mg}(\mathrm{DS})_{2}$ ).

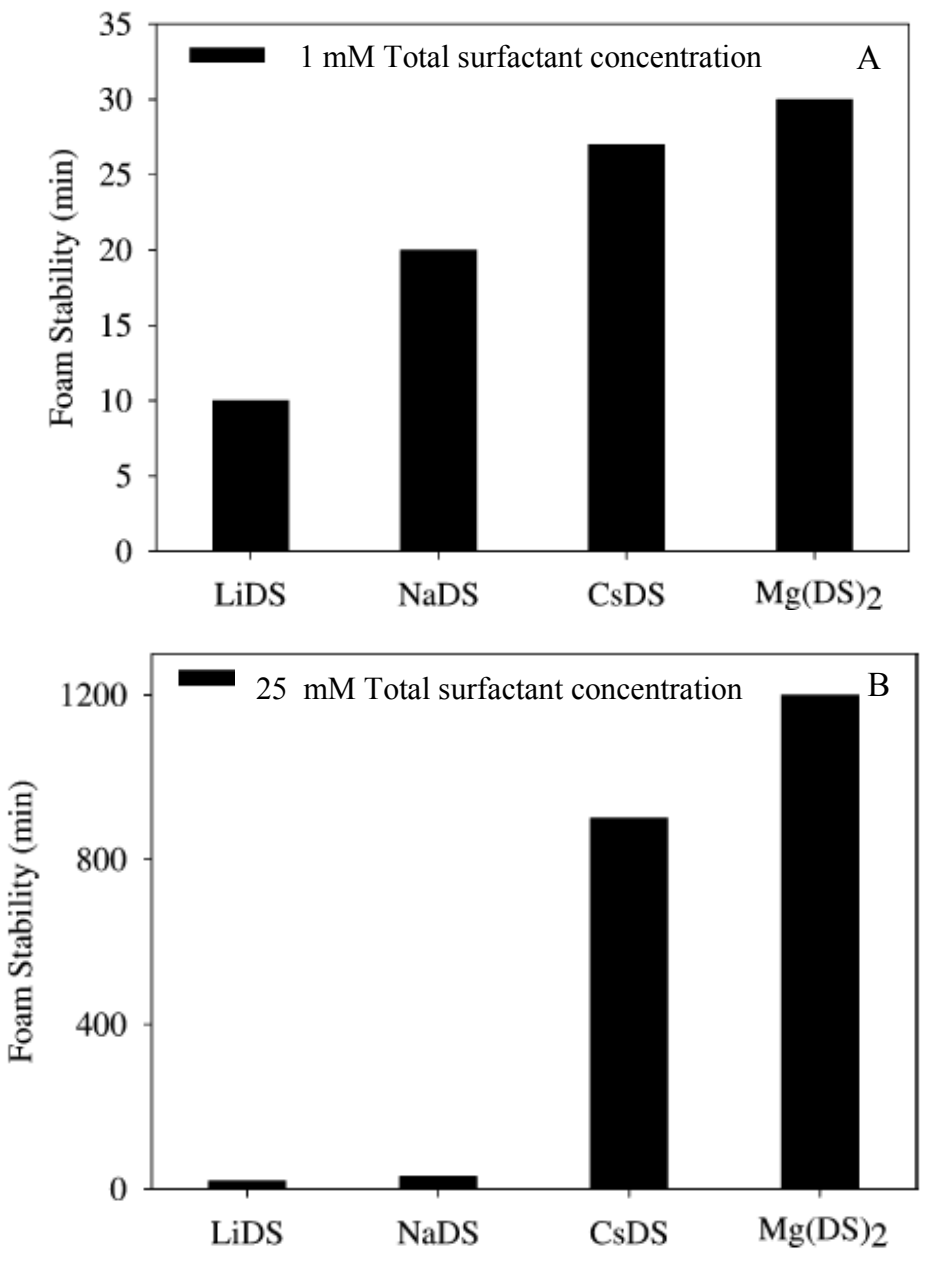


Figure 2. Foam stability of surfactant Dodecylsulfate at A: $1 \mathrm{mM}$ and at B: $25 \mathrm{mM}$ surfactant; Reprinted with the permission from Elsevier, Pandey S. Bagwe R.P. and Shah D.O., "Effect of counterions on surface and foaming properties of dodecyl sulfate, J. Colloid Interface Sci, 2003, 267, 160-166 [105].

The same kind of order can be seen in Fig. 2B (for $25 \mathrm{mM}$ surfactant concentration), but surprisingly, the difference between the stability of the first two foams containing LiDS, SDS and that of CsDS was found to be enormous for some reason.

Schelero et. al. [105], investigated the total disjoining pressure versus the thickness of foam films (measured by means of the film pressure balance setup) stabilized by LiDS, SDS and CsDS at different surfactant concentrations (see Fig.3).

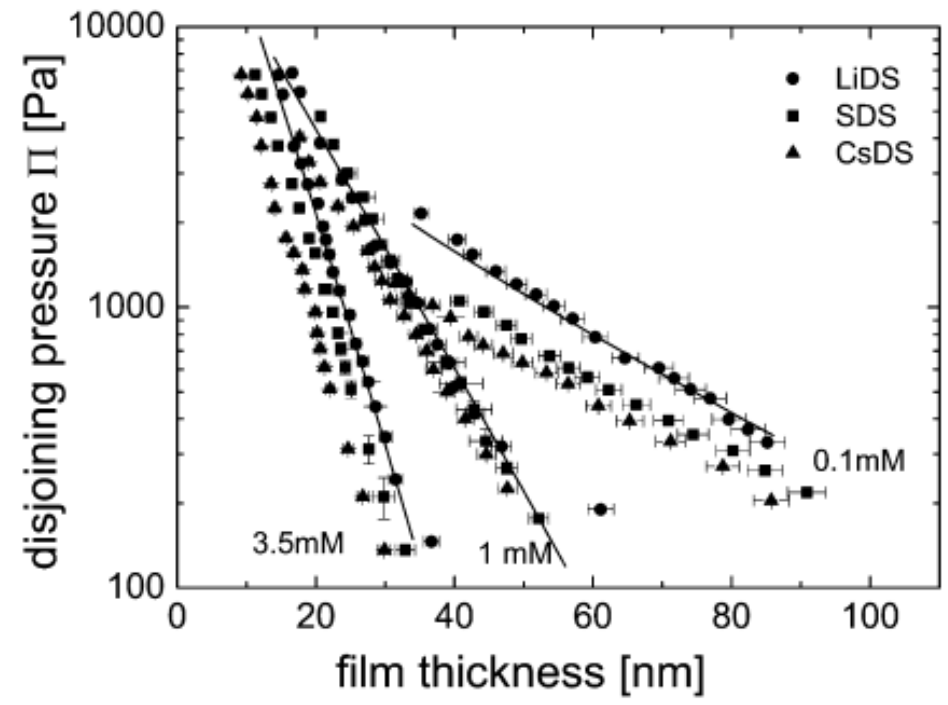

Figure 3. Disjoining pressure $\Pi$ versus film thickness of LiDS (filled circles), SDS (filled squares), and CsDS (filled triangles) at concentrations of $\mathrm{DS}^{-}: 0.1 \mathrm{mM}, 1 \mathrm{mM}$, and $3.5 \mathrm{mM}$. Results for Poisson-Boltzmann calculations are also given (solid curves), and for clarity, only some fitted isotherms are shown; Reprinted with the permission from the Americal Chemical Society, Schelero N., Hedicke G., Linse, P., v. Klitzing R., "Effects of Counterions and Coions on Foam Films Stabilized by Anionic Dodecyl Sulfate", J. Phys. Chem. B, 2010,114, 15523-15529.

One can see in Fig. 3, that the electrostatic repulsion between the foam film surfaces increases in the order CsDS, SDS, LiDS. This is due to the different level of penetration of the counter-ions into the surfactant adsorption layer. The latter increases in the order $\mathrm{Li}^{+}, \mathrm{Na}^{+}$, $\mathrm{Cs}^{+}$, thus making the electrostatic repulsion between the film surfaces decrease in the same order. This is in line with the DLVO theory and should predict the effect of the counter-ions on foam stability - the most stable foams should be produced in the presence of LiDS, while 
the fastest decaying foams should be produced in presence of CsDS. As seen in Fig. 2, the experimental data are opposite to the DLVO theory predictions.

Similar experiments were conducted by Ivanov et al. [106] (see Fig.4), who studied the dependence of the total disjoining pressure on the film thickness of foam films stabilized by mixture of $1 \mathrm{mM}$ cetyltrimethyl ammonium bromide (CTAB) and $\neq 9 \mathrm{mM} \mathrm{NaX}(\mathrm{X}=\mathrm{F}, \mathrm{Cl}$, $\mathrm{Br}$ ). In contrast to Refs. [21] and [105], Ivanov et al. added different salts into the aqueous solution of CTAB, thus easily changing the type the surfactant's counter-ion.

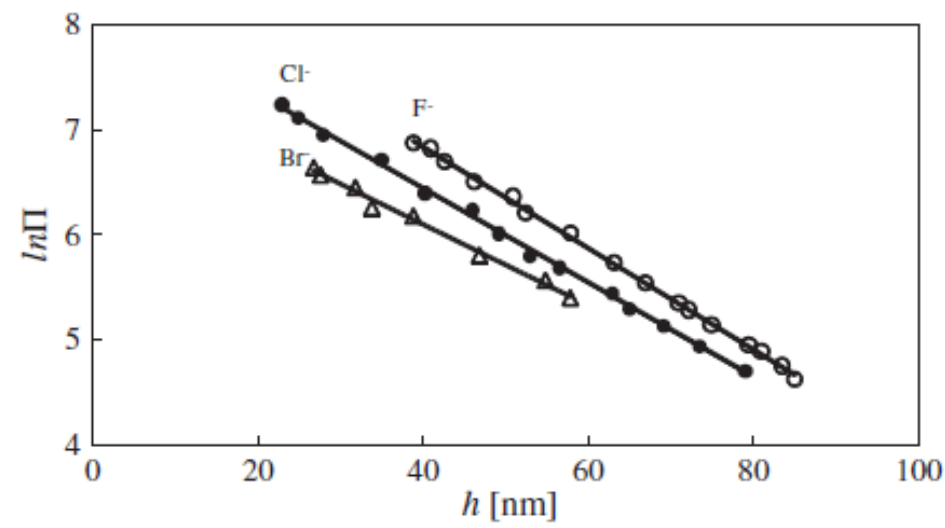

Figure 4. Plot of $\ln \Pi$ versus $h$ for foam films stabilized by $1 \mathrm{mM}$ CTAB $+9 \mathrm{mM} \mathrm{NaX}$ $(\mathrm{X}=\mathrm{F}, \mathrm{Cl}, \mathrm{Br})$; Reprinted with the permission from Elsevier Ivanov I.B., Slavchov R.I., Basheva E.S., Sydzakova D., Karakashev S.I. "Hofmeister effect on micellization, thin films and emulsion stability”, Advances in Colloid and Interface Science, 2011, 168, 93-104.

One can see that even in the presence of a small amount of added salt, the electrostatic stabilization of the foam films works [79, 106]. The strongest repulsion (measured by means of the film pressure balance setup), also leading to the most stable liquid film between the bubbles occurs in presence of $\mathrm{NaF}$, due to the weakest penetration of the charge-dense $\mathrm{F}^{-}$ counter-ions into the surfactant adsoprtion layer. The weakest repulsion between the bubbles takes place in the presence of $\mathrm{NaBr}$, due to the strongest penetration of $\mathrm{Br}^{-}$counter-ions into the surfactant adsoprtion layer.

So how does the type of counter-ions affect the stability of foams/emulsions containing ionic surfactants? To shed a light on this problem, more experimental data are needed. While the experimental data on foam films [21], shown in Fig.4 agree with the DLVO theory, experiments on emulsion stability with the same surfactant system [CTAB + $\mathrm{NaX}(\mathrm{X}=\mathrm{F}, \mathrm{Cl}, \mathrm{Br})$ ] contradict our theoretical expectation similarly to Fig.2 reported inby ref. [21]. These particular emulsions studied in ref. [105] were most stable in presence of $\mathrm{Br}^{-}$ions 
and least stable in presence of $\mathrm{F}^{-}$ions despite the fact that the strongest electro-static repulsion is in the presence of $\mathrm{F}^{-}$counter-ions, and the weakest electro-static repulsion is in the presence of $\mathrm{Br}^{-}$counter-ions. This intriguing result and the results reported in refs. [21] and [105] challenged us to investigate this scientific problem deeper. We have two factors acting in two opposite directions on the film stability - stronger adsorption to the interface results in lower electrostatic repulsion and potentially less stable films, though simultaneously more surfactant adsorption increases surface elasticity and foam film stability. For more diffuse-charge counter-ions penetrating deeper into the surfactant layer (e.g. Br ${ }^{-}$), given enough time, the net surface potential would have lower electrostatic repulsion towards other bubbles (oil droplets)

but also higher adsorption of the surfactant counter-ions, which would support the formation of stable black films. The latter may be made even more stable electrostatically when the distance between the two approaching surfaces becomes smaller than the Debye length, leading to partial expulsion of the counter-ion layer and additional charge stabilization. The results vary, however, with specific foam stability challenge tests, and often time-dependent dynamics may play a role, rather than just equilibrium considerations. So even in this twofactor competition process it is not easy to predict which effect will be stronger.

Further below we present new results that affect the competition between these two effects, where the decrease of electrostatic charge is not balanced by an increase in elasticity. This leads to a maximum stability of a foam below a critical salt concentration, likely caused by surfactant aggregates which don't allow efficient packing at the surface.

There are reports in the literature about the effects of the added salts on the stability of foams in presence of nonionic surfactants. In the absence of electrostatic stabilization, the theoretical predictions for the stability of such films are only at a nascent level. Below we outline some of the achievements and approaches in the literature in this field.

\subsection{The effect of added salts on the properties of foams and foam films stabilized by nonionic surfactants.}

Karakashev and Manev [106] reported that the different monovalent salts have different effects on the foam stability and the foamability of aqueous solutions of nonionic surfactants. Some salts do not affect the stability of such foams, others make the foams more stable, while third ones decrease their lifetime. It was shown that the anion is dominating, but 
the reason for this effect remained unclear (see Fig.5) as well. In the system with $0.5 \mathrm{mM}$ Octaethyleneglycol Mono-n-Decylether $\left(\mathrm{C}_{10}(\mathrm{EO})_{8}\right)$ chloride ions $\left(\mathrm{Cl}^{-}\right)$do not affect the foam stability, the iodide ions $\left(\mathrm{I}^{-}\right)$make the foam more stable, while the bromide ions $\left(\mathrm{Br}^{-}\right)$ decrease the foam stability.

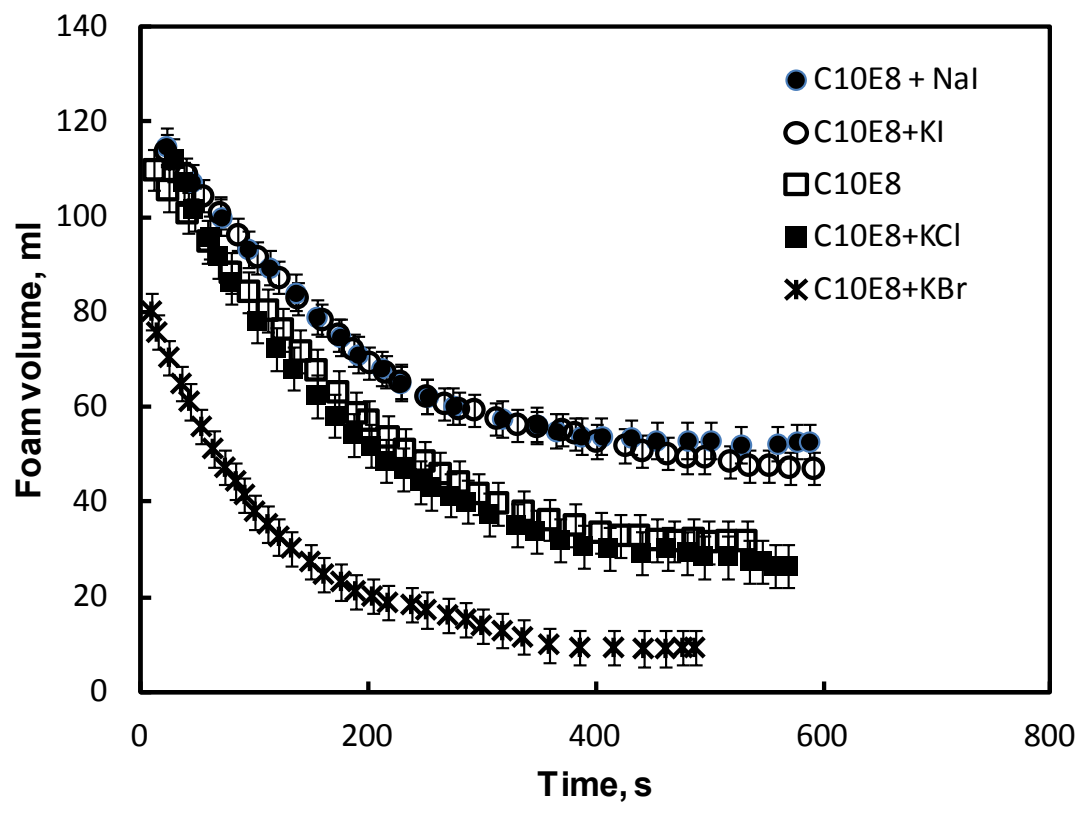

Figure 5.Comparison of the stability of foams, obtained from $0.5 \mathrm{mM}$ Octaethyleneglycol Mono-n-Decylether $\left(\mathrm{C}_{10}(\mathrm{EO})_{8}\right) ; 0.5 \mathrm{mM} \quad \mathrm{C}_{10}(\mathrm{EO})_{8}+10 \mathrm{mM} \mathrm{KBr} ; 0.5 \mathrm{mM} \quad \mathrm{C}_{10}(\mathrm{EO})_{8}+$ $10 \mathrm{mM} \mathrm{KCl} ; 0.5 \mathrm{mM} \mathrm{C}_{10}(\mathrm{EO})_{8}+10 \mathrm{mM}$ NaI; $0.5 \mathrm{mM} \quad \mathrm{C}_{10}(\mathrm{EO})_{8}+10 \mathrm{mM}$ KI. Reprinted with the permission from Elsevier, Karakashev, S.I. and Manev, E.D. "Frothing behavior of Nonionic Surfactant Solutions in the Presence of Organic and Inorganic Electrolytes", J. Colloid Interface Sci, 2001, 235(1), 194-196.

Unfortunately, the effects of the type of the anion on the foam stability in still unclear. Pugh and Manev [107] investigated the effect of potassium chloride $(\mathrm{KCl})$ as added salt on the lifetime of foam stabilized by Pentaehyleneglycol mono-n-dodecyl ether $\left(\mathrm{C}_{12}(\mathrm{EO})_{5}\right)$ and Pentaehyleneglycol mono-n-decyl ether $\mathrm{C}_{10}(\mathrm{EO})_{5}$. They found out that $\mathrm{KCl}$ acts as a foam stabilizer or foam de-stabilizer depending on its bulk concentration. 


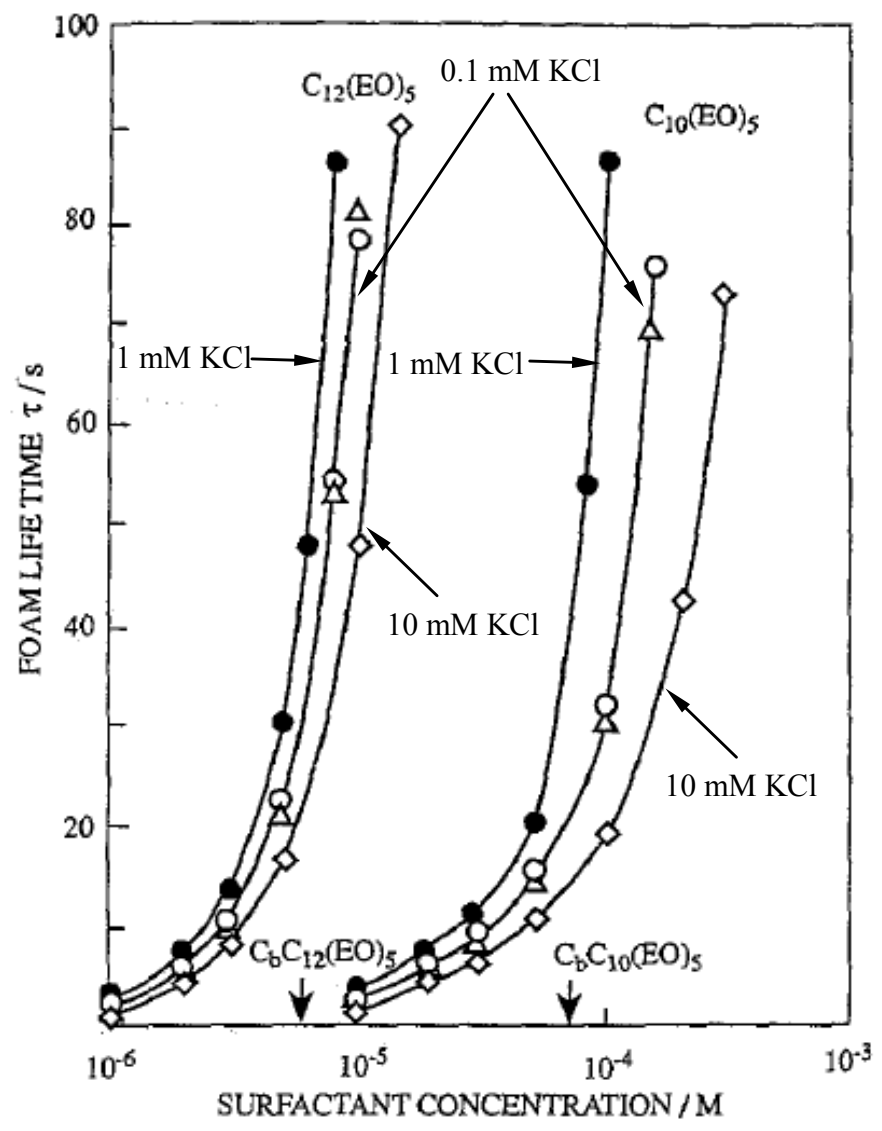

Figure 6. Dependence between foam lifetime and the concentration of $\mathrm{C}_{12}$ (EO) ${ }_{5}$ and $\mathrm{C}_{10}$ (EO) 5 surfactants in double-distilled water in the presence of $0.1 \mathrm{mM} \mathrm{KCl}, 1 \mathrm{mM} \mathrm{KCl}$ and 10 $\mathrm{mM} \mathrm{KCl}$; Reprinted with the permission from Elsevier, Pugh R. and Manev, E.D. "Froth Stability in Aqueous Solutions of Nonionic Surfactant and Inorganic Electrolyte", J. Colloid Interface Sci, 1992, 152(2), 582-584[107-109].

This dual effect of $\mathrm{KCl}$ on the foam stability of ethoxylated nonionic surfactant remained mysterious. Another mystery are the properties of foam films stabilized by nonionic surfactants in the presence of inorganic electrolytes[110]. The thickness of the foam films varies significantly (see Fig.7) and non-linearly with the increase of the concentration of the 
nonionic surfactant at a constant salt concentration. The latter cannot be explained with the classical DLVO theory. Moreover, it is well-known that the nonionic surfactants are not charged and there is no obvious reason for this anomalous variation of the film thickness.

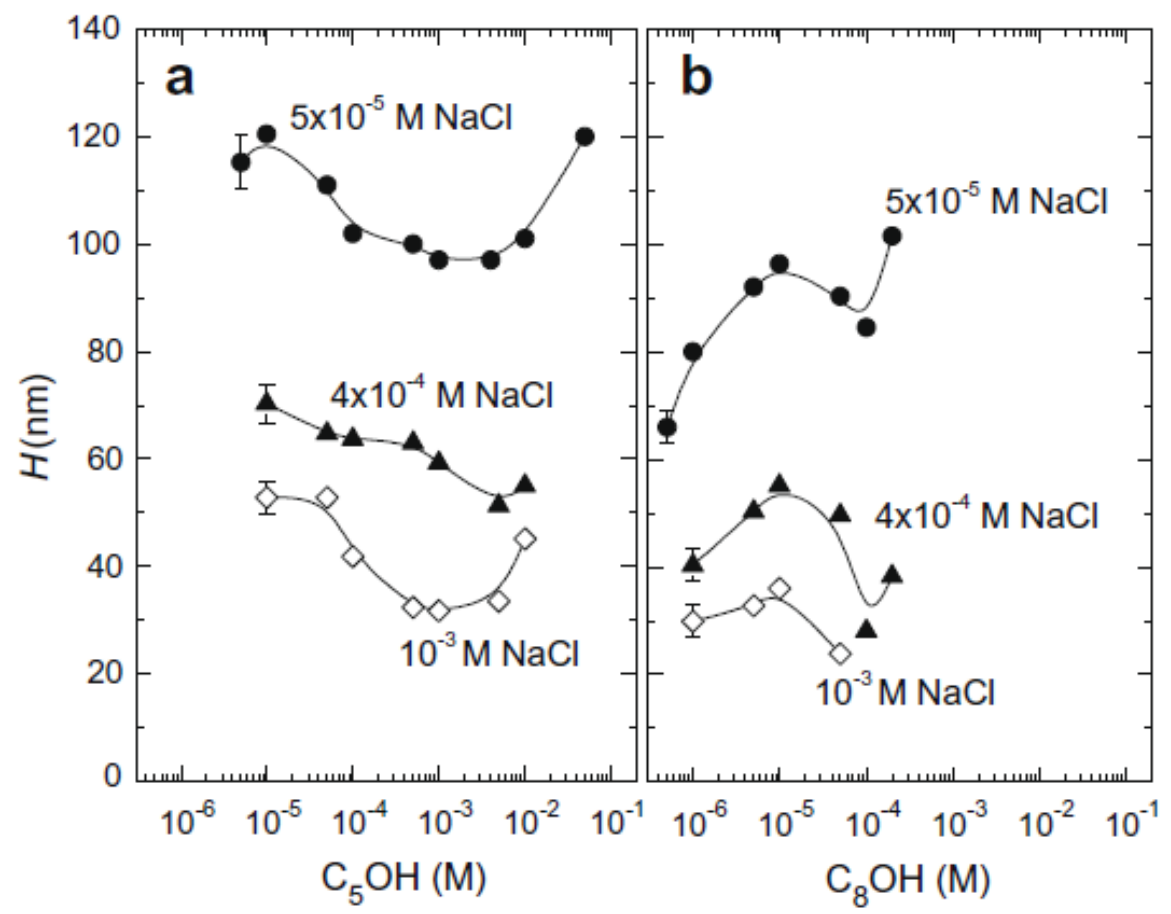

Figure 7. Constant film thicknesses as a function of n-pentanol concentration (a) and $\mathrm{n}$-octanol concentration (b) at varying $\mathrm{NaCl}$ concentrations; Reprinted with the permission from Elsevier, Qu, X., Wang, L., Karakashev S.I., Nguyen A.V., "Anomalous Thickness Variation of the Foam Films Stabilized by Weak Nonionic Surfactants", J. Colloid Interface Sci, 2009, 337, 538-547[109] .

Hence, despite the wide use of non-ionic surfactants in foam films or foam media containing salts, the effects of the addition of different salts, such as the behavior shown in Fig. 7, have not been explained till present. Complete theories about this behavior are lacking and first steps in this direction are made by attempts to model the interactions of ions with water molecules at the air-water interface..

\subsection{The effect of added salts on the properties of the air-water interface.} Formatted: Indent: First line: 0 " 
It is well-known that the water molecules at the interface with air are directed with their oxygen atoms towards the air phase, $[111,112]$, while their hydrogen atoms are directed towards the aqueous phase, thus creating a capacitor with the upper plate being negatively charged and the lower plate being positevly charged. The interaction of the salt ions with this capacitor, in the presence or absence of an adsorption layer of non-ionic surfactants, have been investigated by means of molecular-dynamic simulations (e.g. [111]). Spatial separation of the anions and the cations at close proximity to the air/water interface has been reported[113].

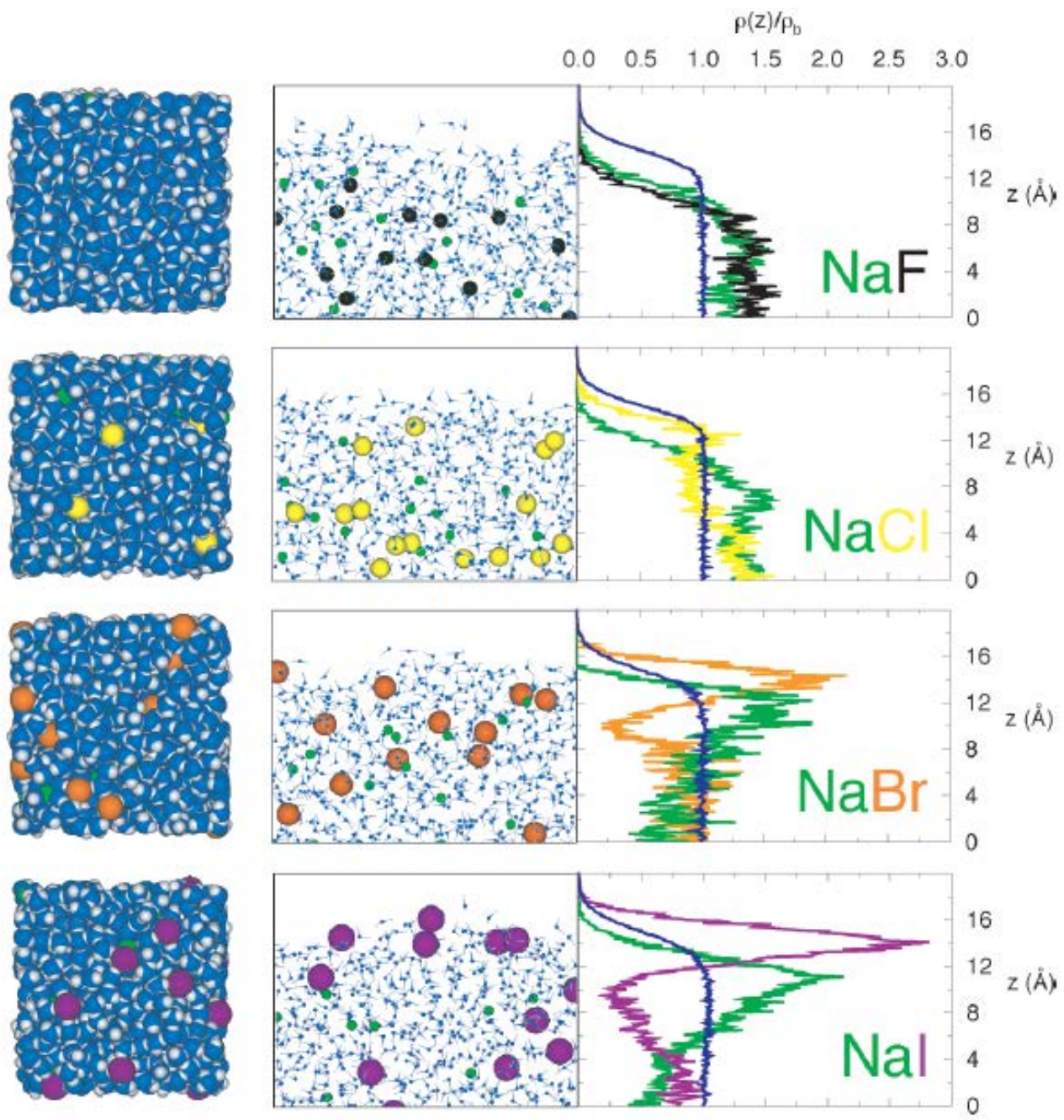

Figure 8. Snapshots (top and side views) of the solution/air interfaces of $1.2 \mathrm{M}$ aqueous sodium halides from the molecular dynamics simulations and density profiles (number 
densities) of water oxygen atoms and ions plotted vs distance from the center of the slabs in the direction normal to the interface, normalized by the bulk water density; Reprinted with the permission from American Chemical Society, Jungwirth, P., and Tobias, D.J., "Ions at the air/water interface”, J. Phys.Chem. B,, 2002, 106, 6361-6374.

The utilization of molecular dynamic simulations (MDS, see Fig.8) to determine the properties of the air / water interface in the presence of salt ions is not an easy task and requires special selection of proper molecular field. Moreover, numerical calculations have their pros and cons. One of the basic disadvantages ${ }_{2}$-due to the significant computation time for MDS, is that the concentration profiles of the ions rarely reach equilibrium configurations. Hence, we need a qualitative theory for calculating the properties of the air/water interface. As mentioned above, the surface water molecules have a specific orientation towards the gas phase, thus creating surfaces with an excess dipole moment. According to the classical macroscopic Maxwell equation, an ion, located at close proximity to such an surface cannot interact with the latter. The surface dipole moment can be assumed to be an extremely thin capacitor, while the classical electrostatic theory states that there is no field beyond the plates of the capacitor. This is somehow a paradox contradicting the experimental results - the ions are attracted or repelled by each one of the dipoles on the surface, but the integrated force is zero. However, this paradox does not exist in the higher orders of the macroscopic approximations of the-electrodynamics. The macroscopic equation of Poisson is valid for a medium, containing fixed electrostatic charges.

It accounts for the dipole moment of the molecules of the medium by means of the Formatted: Indent: First line: $0.38 "$ dielectric permitivitty, but it completely neglects the quadrupole and electric moments of higher orders.

In general, the macroscopic equation of Poisson is a development in a series of multipoles in order of the dipole members. The next higher order approximation accounts for the quadrupole moments of the particles of the medium[112]:

$$
\frac{\mathrm{d} E}{\mathrm{~d} z}-L_{Q}^{2} \frac{\mathrm{d}^{3} E}{\mathrm{~d} z^{3}}=\frac{\rho}{\varepsilon}
$$

where $E$ is the intensity of the electric field, $\rho$ is the density of the free charges, $\varepsilon$ is the dielectric permitivitty (related to the dipole moments and the polarizability of the molecules), while the quadrupole length $L_{Q}$ is a material feature, which is proportional to the quadrupole moments and the quadru-polarizabilities of the particles (for water, the value is $L_{Q} \approx$ $2 \AA[113])$. The quadrupole correction stems from the third derivative of the electric field. The equation of the electrostatics in the quadrupolic approximation in contrast to the classical one, 
is an equation of the third order and needs boundary conditions, which do not exist in classical electrodynamics. The new boundary condition relates the jump of the field gradient with the dipole moment $P_{z}^{s}$ of the surface:

$$
\left.L_{Q}^{2} \frac{\mathrm{d} E}{\mathrm{~d} z}\right|_{z=0}=\frac{P_{z}^{\mathrm{S}}}{\varepsilon}
$$

In the classical Maxwell equation the dipole moment of the surface is absent and consequently it does not interact with the ions, located in the bulk. At higher orders of approximation the macroscopic bulk quadrupolization (the left hand side term of Eq.(9)) is conjugated with the dipole moment of the surface similarly to the conjugation between the bulk polarization and the surface charge in Gauss's law. In the limits of Eqs.(8) and (9) the interaction between the ions and the dipole moment of the surface will occur. Therefore, if the partially positive end of the dipole moment on the surface is directed towards the aqueous phase, itthis will cause preferential adsorption of the anions. The preliminary analysis shows that this adsorption is $-\Gamma \square\left(P_{z}^{s}\right)^{2}$. It corresponds to the surface electrostatic potential $\phi^{s} \square P_{z}^{s}$. A quantitative theory of this phenomenon is difficult to be developed due to several factors - (i) the dipole moment of the air/water interface is significant, thus causing a nonlinear Boltzmann distribution, which makes the solution of Eq. (8) difficult; (ii) the image force should be included in the Boltzmann distribution; (iii) the dipole moment of the air/water interface is a function of the electrical field, which depends on the salt concentration and is hard to define iteratively. Unfortunately, a proper quantitative theory predicting the properties of the air / water interface in the presence of salts is not yet developed due to the above mentioned difficulties. Once this theory is developed, the additional presence of a nonionic surfactant dipoles at the air/water interface does not change qualitatively the general physics of the above mentioned phenomena, and would be welcome for better predictions of nonionic foam systems.

As mentioned in the above sub-chapters, the present state of the theory on the ionspecific effects on foams is poor. For this reason, more experimental data are needed for shedding a light on these effects. Regarding the-foams; stabilized by ionic surfactants, we certainlty know that one of the effects is electro-static stabilization, which is related with the level of penetration of the counter-ions in the surfactant adsoprtion layer. There is another factor, which overcomes the electro-static stabilization, contrary to expectation from DLVO theory. Thus, we were challenged to investigate deeper the nature of this effect. We 
investigated the effects of the cations from $\mathrm{LiCl}, \mathrm{NaCl}$ and $\mathrm{KCl}$ on the stability of foams and vertical foam films stabilized by sodium dodecyl sulfate (SDS). The salts were added in amounts significantly exceeding the concentration of the surfactant.

We clearly show here that electrostatic repulsion between bubbles, which is controlled by the added counter-ions, is only one of the factors contributing to foam stabilization. The counter-ions strongly affect the level of surfactant adsorption as well. The latter appears to be decisive for the stabilization of the foam and the foam films. We show two distinct regimes of surfactant behavior: a) stabilization with added salt, and a previously unobserved effect b) a critical concentration of counter-ions, beyond which rapid destabilization of the films occurs. This concentration is much lower than concentrations known to cause surfactant precipitation or formation of micelles. We believe these observations point to surfactant organization in some pre-micellar aggregates and have practical significance for controlling foam stability.

\section{ION-SPECIFIC EFFECTS ON THE STABILITY OF FOAMS AND FOAM FILMS- STABILIZED BY SODIUM DODECYLSULFATE (SDS) AND ADDED SALT}

We describe in this section our latest contribution to understanding the nature of the ion-specific effects on the stability of foams. We have to confess that we were surprised during the course of the our studies due to unexpected phenomena, whose origine appeared to be ion-specificity. We have chosen sodium dodecyl sulfate (SDS) as the only investigated surfactant in our work because: (i) it is a well--known simple model surfactant, which has been widely investigated in the literature; (ii) it is an inexpensive-cheap, non-toxic detergentwidely used in the commercial cleaning and health care products. StillHence, despite being well investigated ${ }_{2}$ some anomalous effects related to this surfactant are not excluded. Moreover, from a practical point of view ${ }_{2}$ the effects, which were discovered in the present work ; can be used for controlling the foam stability oin industrial scale.

\subsection{Experimental}

Formatted: Font: $12 \mathrm{pt}$

Formatted: Indent: Left: $0 "$

Materials. Sodium dodecyl sulfate (SDS), an anionic surfactant, lithium chloride (LiCl), sodium chloride $(\mathrm{NaCl})$, and potassium chloride $(\mathrm{KCl})$ were purchased from Sigma Aldrich. Initially, $0.5 \mathrm{~g}$ of SDS was added to $300 \mathrm{ml}$ of ethanol. The solution was kept on a hot plate at $80{ }^{\circ} \mathrm{C}$ and stirred until SDS dissolved completely. Then, $0.5 \mathrm{~g}$ of SDS was added to the same 
solution and stirred until the SDS dissolved completely. The addition of SDS was repeated until no further SDS dissolved in ethanol. It was found that the maximum amount of SDS that could be dissolved in this process was $3 \mathrm{~g}(1 \mathrm{~g} / 100 \mathrm{ml}$ ethanol). This solution was then cooled and placed in a refrigerator for $2 \mathrm{~h}$ which resulted in crystallization of SDS. After that, ethanol was drained out and the solution container was again kept on the hot plate at $80^{\circ} \mathrm{C}$. Fresh ethanol was added to SDS crystals until the entire SDS dissolved. This was repeated three times to remove any traces of dodecanol in SDS.

Solution Preparation. SDS salt mixture solutions were prepared as follows. Initially, using SDS, $0.5 \mathrm{mM}$ aqueous solution was prepared by adding $0.014 \mathrm{~g}$ of SDS in $100 \mathrm{ml}$ of deionized water. Then, $0.047 \mathrm{~g}, 0.106 \mathrm{~g}, 0.148 \mathrm{~g}$, and $0.191 \mathrm{~g}$ of $\mathrm{LiCl}$ were added to four separate $0.5 \mathrm{mM}$ aqueous SDS solutions to have $\mathrm{LiCl}$ concentrations of $11 \mathrm{mM}, 25 \mathrm{mM}, 35$ $\mathrm{mM}$, and $45 \mathrm{mM}$, respectively. Similarly, $\mathrm{NaCl}$ and $\mathrm{KCl}$, were added to different $0.5 \mathrm{mM}$ SDS aqueous solutions forming salt solutions with different concentrations $-11 \mathrm{mM}, 25 \mathrm{mM}$, $35 \mathrm{mM}$ and $45 \mathrm{mM}$, etc.

\section{Experimental Setups and Methods.}

Vertical foam film. The experimental setup and method used to study drainage of vertical planar films are described biny ref [114]: A fixed aluminum wire frame (4 cm x $4 \mathrm{~cm} \times 0.087$ $\mathrm{cm}$ ) (see Fig. 9), which supports the film was dipped into a $200 \mathrm{ml}$ container with a solution.
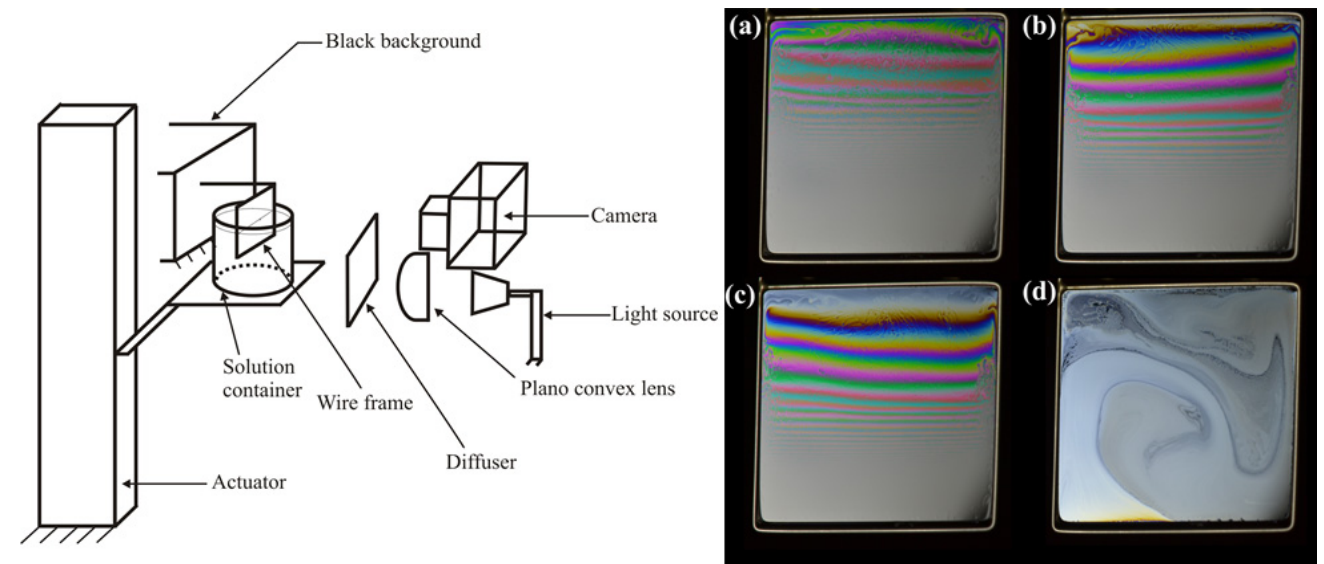

Figure 9. (Left) Schematic of the experimental setup with drainage from plane films[114]. (Right) Images of the time evolution of a vertical foam film stabilized by $0.5 \mathrm{mM}$ SDS +25 $\mathrm{mM} \mathrm{KCl} \mathrm{(a)} t=0 \mathrm{~s}$, (b) $t=18 \mathrm{~s}$, (c) $\mathrm{t}=36 \mathrm{~s}$, and (d) $\mathrm{t}=54 \mathrm{~s}$. 
The solution container was raised and lowered using a linear stage. The film was illuminated perpendicularly with coherent polychromatic light. The latter was reflected by the two surfaces of the film, thus resulting in an interference pattern (see Fig. 9, right), whose time evolution was captured by a CCD camera (Phantom Miro-4) and stored in computer for further off-line processing. The interference pattern obtained from a certain spot of the film (right below the top wire and $2 \mathrm{~cm}$ from the left wire) was processed for obtaining the local film thickness at the very spot versus time. In all of the cases we have established linear dependence of the film thickness on time until the formation of black film, which does not thin anymore, but endure for a certain time until rupturing. The corresponding values of the surface elasticity $\varepsilon$ can be calculated using the equation[114]

$$
\mathrm{T}=\frac{\varepsilon}{\rho\left(\mathrm{gh}_{0}\right)^{3 / 2}}
$$

where $\mathrm{T}$ is characteristic time of film drainage until film rupture, $\rho$ is density of the water, $\mathrm{g}$ is acceleration due to gravity, $\mathrm{h}_{0}$ is the film thickness at the very instant of film formation $(t=0-s e c)$. As far as $\{$ The drainage of the film depends linearly on the time, as it was shown in ref. [114] and is seen in Fig. 10 for $12 \mathrm{mM}$ salt solutions and in Fig. 10S for $25 \mathrm{mM}, 35$ $\mathrm{mM}$, and $45 \mathrm{mM}$ salt solutions.
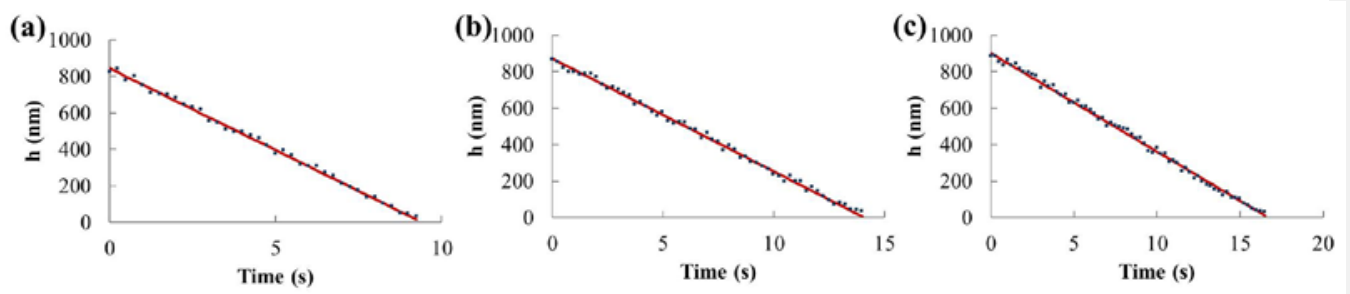

Figure 10. Drainage of plane films of SDS - salt solutions: (a) $11 \mathrm{mM} \mathrm{LiCl,} \mathrm{(b)} 11 \mathrm{mM}$ $\mathrm{NaCl}$, and (c) $11 \mathrm{mM} \mathrm{KCl}$. The data correspond to the film top. The experimental results are shown by symbols. The inclined straight line corresponds to the theoretical prediction of ref[114].

The characteristic time of film drainage was calculated by asymptotical continuation of the experimental drainage curve from the onset of black film until zero nanometers film thickness. Hence, we determined the lifetime of the film and of the black film after its 
formation, the characteristic time for reaching of zero nanometers thickness, the rate of foam film drainage, and the elastic moduli of the foam films.

Foam column experiments. A large amount of uniform foam was created by mechanical mixing. $200 \mathrm{ml}$ of a desired solution was placed in a mixing bowl and the solution was stirred for 3 min using a standard household hand mixer. The experimental method is described in detail elsewhere[115]. The generated foam was then poured into a cylinder (inner diameter of $2.58 \mathrm{~cm}$ and $104 \mathrm{~cm}$ tall) using a funnel-hose system and was filled from the bottom up. The funnel-hose system was raised as the level of foam increased, so that the foam exiting the hose would be on top. The cylinder was capped once the foam was filled to the top of the cylinder, which prevented loss of liquid vapor or air from the cylinder during the entire experiment. The drained liquid height was measured using a CCD camera from which the drainage velocity was calculated.

Surface tension measurements. The surface tension isotherms of $0.5 \mathrm{mM}$ Sodium dodecylsulfate with different concentrations of $\mathrm{LiCl}, \mathrm{NaCl}$, and $\mathrm{KCl}$ were measured by means of profile analysis tensiometry (tensiometer K10ST of Kruss, GmbH, Germany). The whole instrument stands on a stable (vibration-proof) table in a clean dark room with a controlled temperature. The temperature of the test fluid in the cuvette was kept constant at $(20 \pm 0.1){ }^{\circ} \mathrm{C}$ during the experiment using the water bath. The bubble formation and its volume were controlled by the syringe pump using the software. Once formed, the bubble shape was illuminated, equilibrated and its image was captured by the CCD video camera, stored, and processed by the computer software. The edge (the interface profile) of the bubble was digitally detected with sub-pixel resolution and was fitted with the numerical solution of the Young-Laplace equation, allowing the determination of surface tension, volume and area of the bubble. The accuracy in surface tension was in the $\pm 0.2 \mathrm{mN} / \mathrm{m}$ range- $-1 \pm 0.2 \mathrm{mN} / \mathrm{m}$.

\subsection{Results and Discussion}

\subsubsection{Thin film experiments and analysis.}

Shown in Fig. 11Figure 11 shows is the lifetime of the foam lamella containing $0.5 \mathrm{mM}$ Formatted: Indent: First line: $0.38^{\prime \prime}$ SDS at different concentrations of the added salts in the concentration range of $11 \mathrm{mM}-45$ $\mathrm{mM}$. One can see regularity in the cases of $\mathrm{LiCl}$ and $\mathrm{NaCl}$. In the whole concentration range $\mathrm{NaCl}$ stabilizes the foam lamella better than $\mathrm{LiCl}$. On the contrary, the case with $\mathrm{KCl}$ is 
different. It stabilizes the foam lamella better than the other salts only at $11 \mathrm{mM}$ added salt. However, at larger concentrations, it becomes, the worste foam lamella stabilizer. Moreover, at a certain critical concentration $(45 \mathrm{mM}) \mathrm{KCl}$ acts as strong de-stabilizer.

Fig-ure 12 depicts the dependence of the lifetime of the foam lamella, stabilized by 0.5 mM SDS, versus the specific energy of adsorption[79] of $\mathrm{Li}^{+}, \mathrm{Na}^{+}$, and $\mathrm{K}^{+}$(see Table 1) ions on air/water interface in the concentration range of $11 \mathrm{mM}-45 \mathrm{mM}$ of added salt (for more details about the specific adsorption energy of coubnter-ion adsorption see ref. [79])

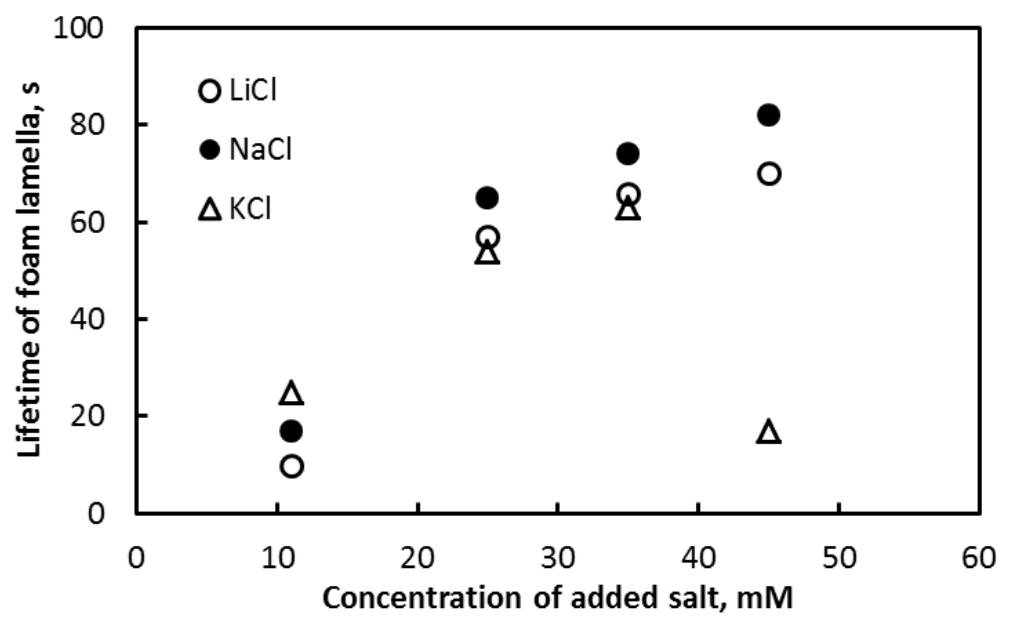

Figure 11. The dependence of the lifetime of the foam lamella on the concentration of the added salt in the presence of $0.5 \mathrm{mM}$ SDS. 

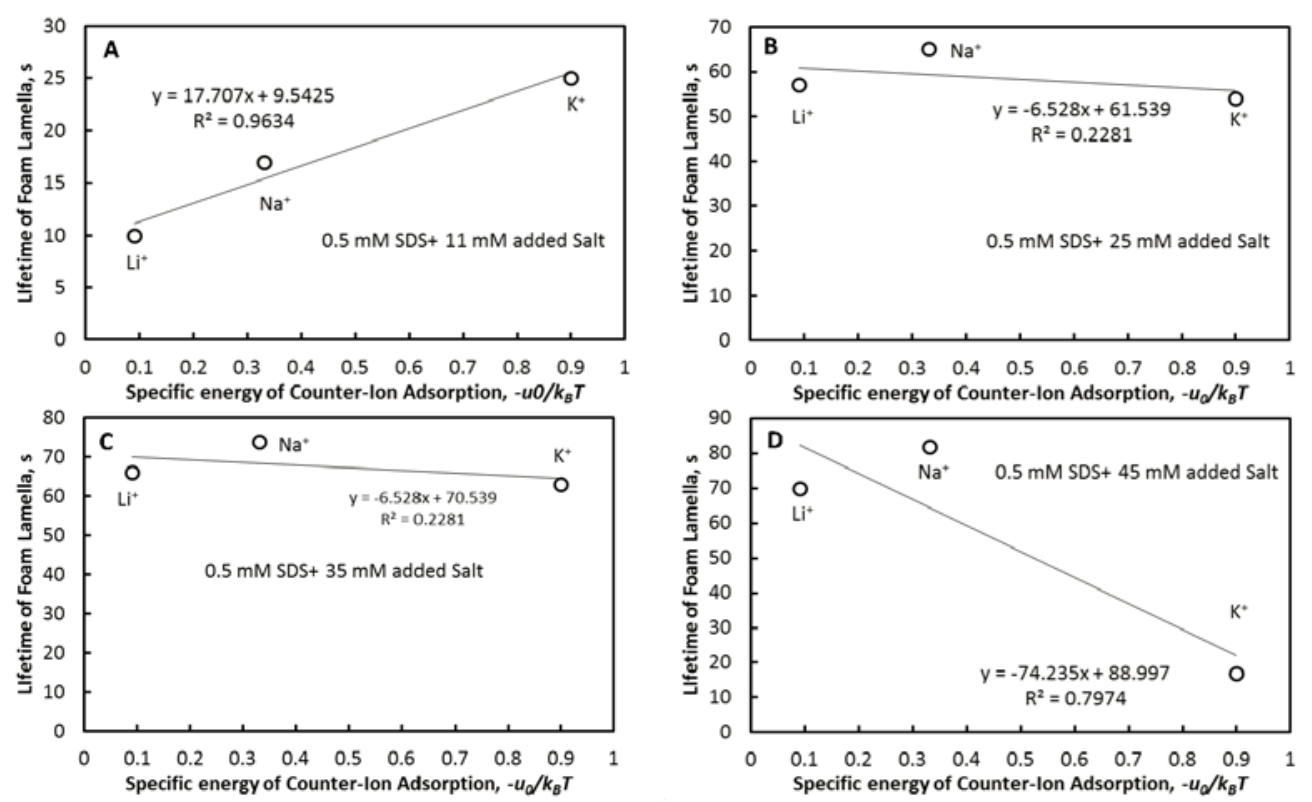

Figure 12. The lifetime of the foam lamella versus the specific energy of counter-ion adsorption for films stabilized by: (A) $0.5 \mathrm{mM} \mathrm{SDS}+11 \mathrm{mM} \mathrm{MCl} \mathrm{(M=Li,} \mathrm{Na,} \mathrm{K);} \mathrm{(B)} 0.5$ $\mathrm{mM} \mathrm{SDS}+25 \mathrm{mM} \mathrm{MCl}(\mathrm{M}=\mathrm{Li}, \mathrm{Na}, \mathrm{K})$; (C) $0.5 \mathrm{mM} \mathrm{SDS}+35 \mathrm{mM} \mathrm{MCl}(\mathrm{M}=\mathrm{Li}, \mathrm{Na}, \mathrm{K})$; (D) $0.5 \mathrm{mM}$ SDS + $45 \mathrm{mM} \mathrm{MCl}(\mathrm{M}=\mathrm{Li}, \mathrm{Na}, \mathrm{K})$.

At $11 \mathrm{mM}$ added salt (Fig.12A), one can see a linear dependence between the lifetime of the foam film and the specific energy of counter-ion adsorption on air/water interface, in line with the results reported in ref. [21]. Fig. 12A shows that the-larger the value of the specific energy of counter-ion adsorption, the-longer is the life of the foam film, as the counter-ions promote higher adsorption of surfactant on the oil/water interface to cause better stabilization.

At larger salt concentrations, however, though the lifetime of the foam films increases, the above-mentioned linear dependence is violated (see Figs. 12B and 12C). At 45 $\mathrm{mM}$ added salt, the $\mathrm{K}^{+}$counter-ion suddenly shows a destabilizing effect - the lifetime of the films falls almost to the level observed without any salt added ( 15s). (see Fig. 12D). Beyond this critical concentration of $45 \mathrm{mM}$ for $\mathrm{KCl}$, higher $\mathrm{KCl}$ concentrations do not shorten the lifetime of the foam films any further.-

To understand the mechanism of the novel behavior in the presence of $45 \mathrm{mM} \mathrm{KCl}$, we analyzed the surfactant adsorption at the air/water interface using experimental surface tension isotherms of $0.5 \mathrm{mM}$ sodium dodecyl sulfate (SDS) in the presence of added in significant excess $\mathrm{LiCl}, \mathrm{NaCl}$, and $\mathrm{KCl}[21,79]$ (see Table 2 and Fig. 13). Table 2 presents the 
lifetimes of the foam lamellas, black films, their initial foam film thicknesses, the characteristic time of foam film drainage, the speed of thinning of the foam films, the experimental elasticity and the Gibbs elasticity (for more details see the supplementary material) of foam films, stabilized by $0.5 \mathrm{mM}$ SDS, in the concentration range of $11 \mathrm{mM}-45$ $\mathrm{mM}$ of added salt.

The surface elasticity of the vertical foam films correlates with the lifetime of the films, the lifetime of the black films, the characteristic time of foam film drainage, and the speed of thinning of the foam films. At $45 \mathrm{mM} \mathrm{KCl}$ all the parameters of the vertical foam film correspond to unstable film - short lifetime, shortersmall characteristic time, fast drainage and small values of the elasticity. At this stage of our investigation we did not observe such anomalies with the addition of $\mathrm{LiCl}$ and $\mathrm{NaCl}$. For this reason, we assumed the effect of $\mathrm{KCl}$ as extraordinary. Yet, we hypothesized that $\mathrm{LiCl}$ and $\mathrm{NaCl}$ should have the same effect at proper concentrations of added salt. One can see a substantial difference between the experimental and the Gibbs elasticity of the foam films. This difference is expectable as far as the Gibbs elasticity and the visco-elastic moduli of the foam films are different values.

Table 2. The lifetimes (see experimental methods) of the foam lamellas, black films, their initial foam film thickness, the characteristic time of foam film drainage, the experimental and Gibbs elasticities in the presence of $0.5 \mathrm{mM}$ SDS and $11 \mathrm{mM}, 25 \mathrm{mM}, 35 \mathrm{mM}$, and $45 \mathrm{mM}$ added $\mathrm{MCl}(\mathrm{MCl}, \mathrm{M}=\mathrm{Li}, \mathrm{Na}, \mathrm{K})$ of added salt.

\begin{tabular}{|c|c|c|c|c|c|c|c|}
\hline $\begin{array}{c}\text { Added } \\
\text { salt }\end{array}$ & $\begin{array}{l}\text { Lifetime of } \\
\text { the film } \\
\text { (s) }\end{array}$ & $\begin{array}{l}\text { Lifetime of } \\
\text { black films } \\
\text { (s) }\end{array}$ & $\begin{array}{c}\mathbf{h}_{0} \\
(\mathbf{n m})\end{array}$ & $\begin{array}{l}\mathbf{T} \\
\text { (s) }\end{array}$ & $\begin{array}{c}\mathrm{U} \\
(\mathrm{nm} / \mathbf{s})\end{array}$ & $\begin{array}{c}\varepsilon \\
(\mathrm{mN} / \mathrm{m})\end{array}$ & $\begin{array}{l}\text { Gibbs } \\
\text { elasticity } \\
(\mathrm{mN} / \mathrm{m})\end{array}$ \\
\hline $11 \mathrm{mM} \mathrm{LiCl}$ & 10 & 9 & 843.7 & 9.4 & 89.8 & 0.22 & 31.4 \\
\hline $25 \mathrm{mM} \mathrm{LiCl}$ & 57 & 38 & 916.2 & 38.5 & 23.8 & 1.04 & 38.36 \\
\hline
\end{tabular}




\begin{tabular}{|c|c|c|c|c|c|c|c|}
\hline $35 \mathrm{mM} \mathrm{LiCl}$ & 66 & 43 & 926.6 & 43.1 & 21.5 & 1.18 & 41.38 \\
\hline $45 \mathrm{mM} \mathrm{LiCl}$ & 70 & 46 & 929.5 & 46.5 & 20.0 & 1.28 & 43.66 \\
\hline $11 \mathrm{mM} \mathrm{NaCl}$ & 17 & 14 & 871.7 & 14.4 & 60.5 & 0.35 & 37.86 \\
\hline $25 \mathrm{mM} \mathrm{NaCl}$ & 65 & 40 & 943.1 & 40.4 & 23.3 & 1.14 & 45.81 \\
\hline $35 \mathrm{mM} \mathrm{NaCl}$ & 74 & 46 & 955.4 & 46.8 & 20.4 & 1.343 & 49.15 \\
\hline $45 \mathrm{mM} \mathrm{NaCl}$ & 82 & 51 & 967.8 & 51.9 & 18.7 & 1.518 & 51.64 \\
\hline $11 \mathrm{mM} \mathrm{KCl}$ & 25 & 16 & 900.6 & 16.7 & 53.9 & 0.439 & 50.31 \\
\hline $25 \mathrm{mM} \mathrm{KCl}$ & 54 & 36 & 917.6 & 36.3 & 25.3 & 0.98 & 58.72 \\
\hline $35 \mathrm{mM} \mathrm{KCl}$ & 63 & 41 & 924.1 & 41.2 & 22.4 & 1.125 & 61.99 \\
\hline $\mathbf{4 5} \mathbf{m M ~ K C l}$ & $\mathbf{1 7}$ & $\mathbf{1 5}$ & $\mathbf{9 0 5 . 3}$ & $\mathbf{1 5 . 5}$ & $\mathbf{5 8 . 4}$ & $\mathbf{0 . 4 1}$ & 64.32 \\
\hline
\end{tabular}

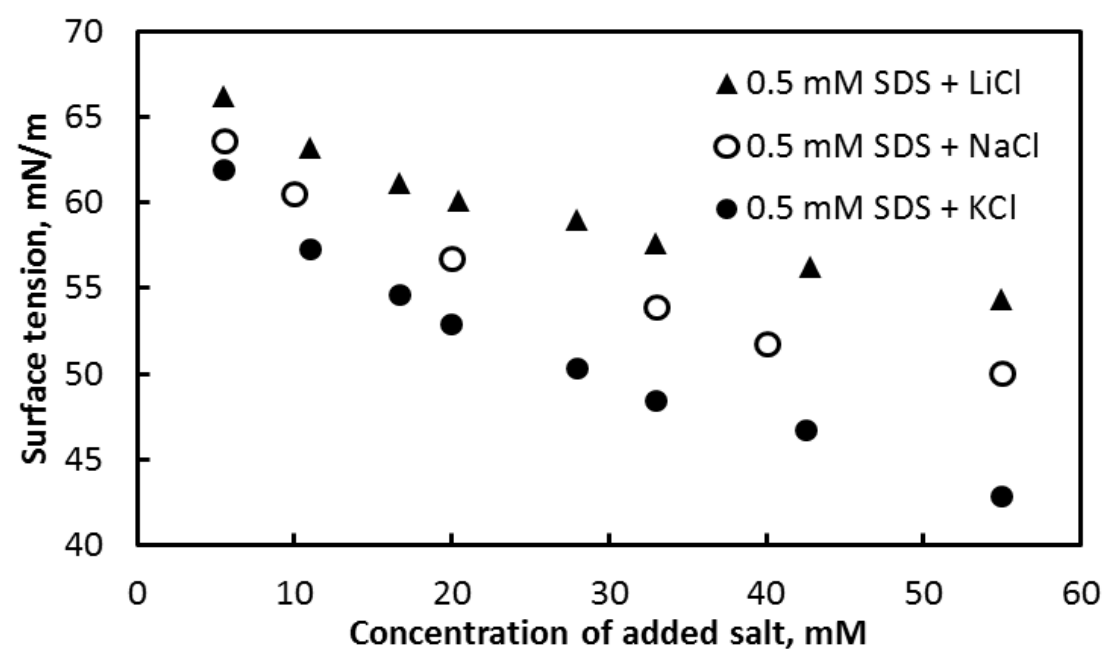

Figure 13. Surface tension isotherms of $0.5 \mathrm{mM} \mathrm{SDS}+$ added salts; The relative experimental error is $\pm 0.2 \mathrm{mN} / \mathrm{m}$.

We Tthen we-applied the adsorption theory of Ivanov et al. [78], which is based on the Formatted: Indent: First line: $0.38^{n}$ equation of state of Helfand-Frish-Lebowitz[116] of a two-dimensional fluid of rigid spheres in the approximation of a-Baxter sticky potential[79, 117]. This model is both productively accurate and phenomenologically instructive. Though initially created with four free 
parameters, recent advances have reduced the free parameters to two[78, 88, 90] (the adsorption constant $K$ and the interaction parameter $\beta$ ). The basic equations of this theory can be expressed by the following surface tension isotherm and equation of state (for more information please see the supplementary material):

$$
\begin{aligned}
& K a^{2 / 3}=\frac{\Gamma_{s}}{\left(1-\alpha_{0} \Gamma_{S}\right)^{1 / 3}}\left(\frac{2}{1+R_{\beta}}\right)^{\frac{1+8 \beta}{12 \beta}} \times \exp \left[\frac{\alpha_{0} \Gamma_{s}\left(4-3 \alpha_{0} \Gamma_{S}\right)}{3\left(1-\alpha_{0} \Gamma_{S}\right)^{2}} \times \frac{2}{1+R_{\beta}}\right] ; R_{\beta}=\sqrt{1+16 \beta \frac{\alpha_{0} \Gamma_{\mathrm{s}}}{1-\alpha_{0} \Gamma_{\mathrm{s}}}} \\
& \quad \frac{\sigma}{k_{B} T}=\frac{\sigma_{0}^{S}}{k_{B} T}-\frac{\Gamma_{S}}{\left(1-\alpha_{0} \Gamma_{S}\right)^{2}} \times \frac{2}{1+R_{\beta}}-2 \Gamma_{S}
\end{aligned}
$$

where $a=\sqrt{a_{s}\left(a_{s}+a_{\text {salt }}\right)}, a_{s}$ and $a_{\text {salt }}$ are activities of the surfactant and the added salt (if addedny), and $-\sigma_{0}^{S}$ is cohesion constant, $K$ is the equilibrium adsorption constant of the surfactant in presence of significant excess of added counter ions by means of added salt, $\alpha_{0}$ is the crosssectional area per adsorbed surface-active ion (DS) $\beta$ is interaction parameter, and $\sigma_{0}^{S}$ is cohesion constant, $\Gamma_{s}$ is adsorption of the surface-active ions $\left(\mathrm{DS}^{-}\right), \sigma$ is surface tension of the air/water interface, $k_{B}$ is Boltzmann constant, and $T$ is absolute temperature. Eqs. (11) and (12) have four matehing fitting parameters: $K, \alpha_{0}, \sigma_{0}^{S}$ and $\beta$. Fortunately, we have found ways for reducing the number of the fitting parameters to two (see the supplementary material).

The Gibbs elasticity of foam films can be determined by means of the following expressions:

$$
E_{G}=-2 \frac{d \sigma}{d \ln \Gamma}
$$

Hence, one can combine Eqs. (11) and (12) thus obtaining expression for the Gibbs elasticity of foam film as: 


$$
E_{G}=-2 \Gamma\left[\begin{array}{c}
-\frac{2 k_{B} T}{\left(1-\alpha_{0} \Gamma\right)^{2}\left(1+\sqrt{1+\frac{16 \beta \alpha_{0} \Gamma}{1-\alpha_{0} \Gamma}}\right)}-\frac{4 \Gamma k_{B} T \alpha_{0}}{\left(1-\alpha_{0} \Gamma\right)^{3}\left(1+\sqrt{1+\frac{16 \beta \alpha_{0} \Gamma}{1-\alpha_{0} \Gamma}}\right)}+ \\
+\frac{\Gamma k_{B} T\left(\frac{16 \beta \alpha_{0}}{1-\alpha_{0} \Gamma}+\frac{16 \beta \alpha_{0}^{2} \Gamma}{\left(1-\alpha_{0} \Gamma\right)^{2}}\right)}{\left(1-\alpha_{0} \Gamma\right)^{2}\left(1+\sqrt{1+\frac{16 \beta \alpha_{0} \Gamma}{1-\alpha_{0} \Gamma}}\right)^{2} \sqrt{1+\frac{16 \beta \alpha_{0} \Gamma}{1-\alpha_{0} \Gamma}}}-2 k_{B} T
\end{array}\right]
$$

This expression was exploited for obtaining the Gibbs elasticity of the investigated vertical foam films. The adsorption parameters, after the analysis of the experimental data, are presented in Table 3, and were used to predict the adsorption of DS- ions as a function of the salt concentration for the three added salts (see Fig. 14). The values of the adsorption parameters presented in Table 3 are reasonable [79]. Thus, for example, the expected range of $K$ for LiDS is $76-105$, for NaDS is $111-123$, for KDS is $151-166$. The expected range of $\beta$ is $0-3$, while thatis one for $\alpha_{0}$ is 20-22. Accordingly, the expected range of $\sigma_{0}$ is 79-85. The cross-sectional area per surfactant molecule (see Table 3) is close to this onethat of the hydrocarbon tail, in contrast to this onethat of the sulfate group, which is larger.

One can see that the surface activity of dodecyl sulfate ions (DS') increases in the order Formatted: Indent: First line: $0.38^{\prime \prime}$ of $\mathrm{Li}^{+}, \mathrm{Na}^{+}, \mathrm{K}^{+}$of the added counter-ions, and at $45 \mathrm{mM} \mathrm{KCl}$ (the first vertical line and critical concentration for $\mathrm{KCl}$ ) the adsorption of $\mathrm{DS}^{-}$ions at the air/water interface is $4.4 \times 10^{-6}$ $\mathrm{mol} / \mathrm{m}^{2}$.

Table 3. Equilibrium adsorption constant $K$, interaction parameter $\beta, \alpha_{0}$ cross-sectional area per surfactant molecule, and the cohesion constant $\sigma_{0}$ of $0.5 \mathrm{mM}$ SDS in the presence of added in excess $\mathrm{LiCl}, \mathrm{NaCl}$, and $\mathrm{KCl}$; The average error in $\sigma_{0}$ is $\pm 0.25 \mathrm{mN} / \mathrm{m}$.

\begin{tabular}{|c|c|c|c|c|}
\hline System & $K$ & $B$ & $\alpha_{0}\left(\AA^{2}\right)$ & $\sigma_{0}(\mathrm{mN} / \mathrm{m})$ \\
\hline $0.5 \mathrm{mM}$ SDS+LiCl & $107.00 \pm 0.3$ & $0.90 \pm 2 \times 10^{-3}$ & $20.75 \pm 0.5$ & $79.85 \pm 0.04$ \\
\hline $0.5 \mathrm{mM} \mathrm{SDS}+\mathrm{NaCl}$ & $122.60 \pm 0.3$ & $1.18 \pm 2 \times 10^{-3}$ & $20.75 \pm 0.5$ & $79.84 \pm 0.04$ \\
\hline $0.5 \mathrm{mM}$ SDS+KCl & $167.22 \pm 0.3$ & $1.36 \pm 2 \times 10^{-3}$ & $20.75 \pm 0.5$ & $84.65 \pm 0.04$ \\
\hline
\end{tabular}




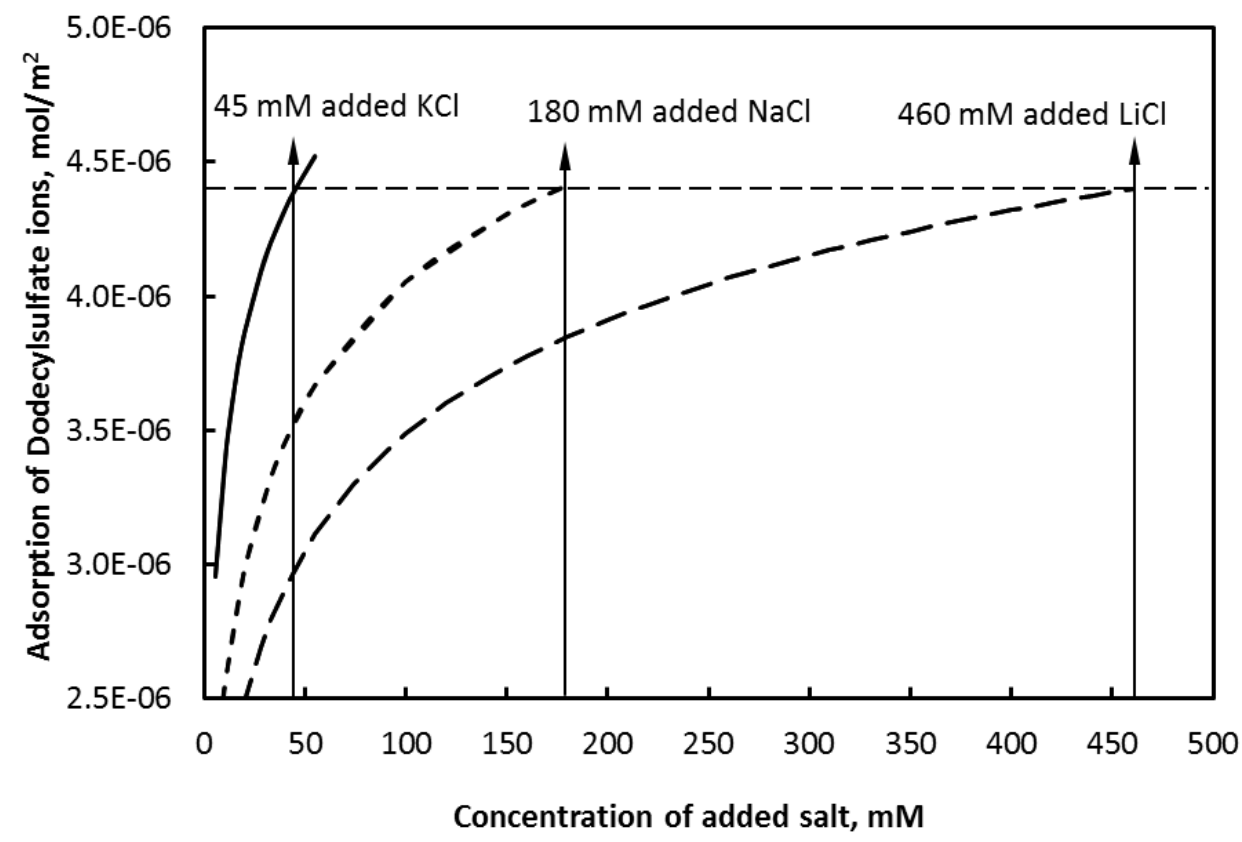

Figure 14. Adsorption of $\mathrm{DS}^{-}$ions on the air/water interface of $0.5 \mathrm{mM}$ SDS as a function of the concentration of added salt $(\mathrm{MCl}, \mathrm{M}=\mathrm{Li}, \mathrm{Na}, \mathrm{K})$ - prediction of level of adsorption at the critical point of foam film de-stabilization; the average error calculation of the adsorption is about $1.5 \%$ (for more information about the modeling of surface coverage see ref.[78, 79]).

We hypothesized that at similar adsorption of $\mathrm{DS}^{-}$ions for the other salts, the foam films may become unstable as well. From Fig. 14, based on the modified model of Ivanov et al. $[79,90]$ we predicted the same adsorption of $\mathrm{DS}^{-}$ions would be achieved at $180 \mathrm{mM} \mathrm{NaCl}$ and $460 \mathrm{mM} \mathrm{LiCl}$ and we might expect to observe corresponding film destabilization for those salts. Indeed, the destabilization occurred exactly at the predicted values, as the results are shown in Table 4.

Table 4. Added salt and corresponding lifetimes of the foam lammelaes, black films, their initial foam film thickness, specific time of foam film drainage, and experimental and Gibbs elasticities (for more information, see the supplementary material) for the cases of $450 \mathrm{mM}$ and $460 \mathrm{mM} \mathrm{LiCl}$ and correspondingly $175 \mathrm{mM}$ and $180 \mathrm{mM} \mathrm{NaCl}$.

\begin{tabular}{|c|c|c|c|c|c|c|c|}
\hline Added & Lifetime & Lifetime of & $\mathbf{h}_{0}$ & $T$ & $\mathbf{U}$ & $\varepsilon$ & Gibbs \\
Salt & of & black films & $(\mathbf{n m})$ & $(\mathbf{s})$ & $(\mathbf{n m} / \mathbf{s})$ & $(\mathbf{m N} / \mathbf{m})$ & elasticity \\
\hline
\end{tabular}




\begin{tabular}{|c|c|c|c|c|c|c|c|}
\hline & film(s) & $\mathbf{( s )}$ & & & & & $\mathbf{( m N / m )}$ \\
\hline $450 \mathrm{mM}$ added LiCl & 95 & 55 & 971.6 & 55.2 & 17.6 & 1.624 & 64.16 \\
\hline $\mathbf{4 6 0} \mathbf{m M}$ added $\mathbf{L i C l}$ & $\mathbf{1 4}$ & $\mathbf{1 3}$ & $\mathbf{8 9 2 . 1}$ & $\mathbf{1 3 . 3}$ & $\mathbf{6 7 . 1}$ & $\mathbf{0 . 3 4 4}$ & 64.35 \\
\hline $175 \mathrm{mM}$ added $\mathrm{NaCl}$ & 103 & 59 & 992.4 & 59.3 & 16.7 & 1.801 & 64.26 \\
\hline $\mathbf{1 8 0} \mathbf{m M ~ a d d e d ~} \mathbf{N a C l}$ & $\mathbf{1 6}$ & $\mathbf{1 4}$ & $\mathbf{9 0 8 . 6}$ & $\mathbf{1 4 . 5}$ & $\mathbf{6 2 . 7}$ & $\mathbf{0 . 3 8 6}$ & 64.50 \\
\hline
\end{tabular}

A hypothesis for the mechanism of destabilization is that salt addition (via screening interactions) serves to pack more DS $^{-}$ions at the interface up to the critical adsorption $\left(\Gamma=4.4 \times 10^{-6} \mathrm{~mol} / \mathrm{m}^{2}\right)$. Upon further addition, the salt causes some precipitation or structuring of the SDS, the surfactant coverage of the interface is suddenly reduced, increasing the surface tension, and resulting in faster drainage. The decrease is not necessarily equilibrium, as for newly formed films, the equilibration of SDS molecules from the new structures may be slower than the drainage of the films, and thus the limiting factor. Once thinned out, the resulting black films (about $30 \mathrm{~nm}$ thickness) have no volume from which to form full layers, and-thus have significantly shorter lifetimes as well, due to the sparser adsorption layer coverage.

The suddenly faster film drainage was consistent with our hypothesis for dynamic, non-equilibrium cause of the shorter lifetimes of the films, if equilibrium concentrations could not be reached. We used a plot of the experimentally determined surface tension and drainage velocities to try and infer the effective surface tension during the faster drainage of the films, and from the adsorption theory of Ivanov et al.[78], the effective equilibrium surfactant coverage of air/water interface (Fig. 15). 


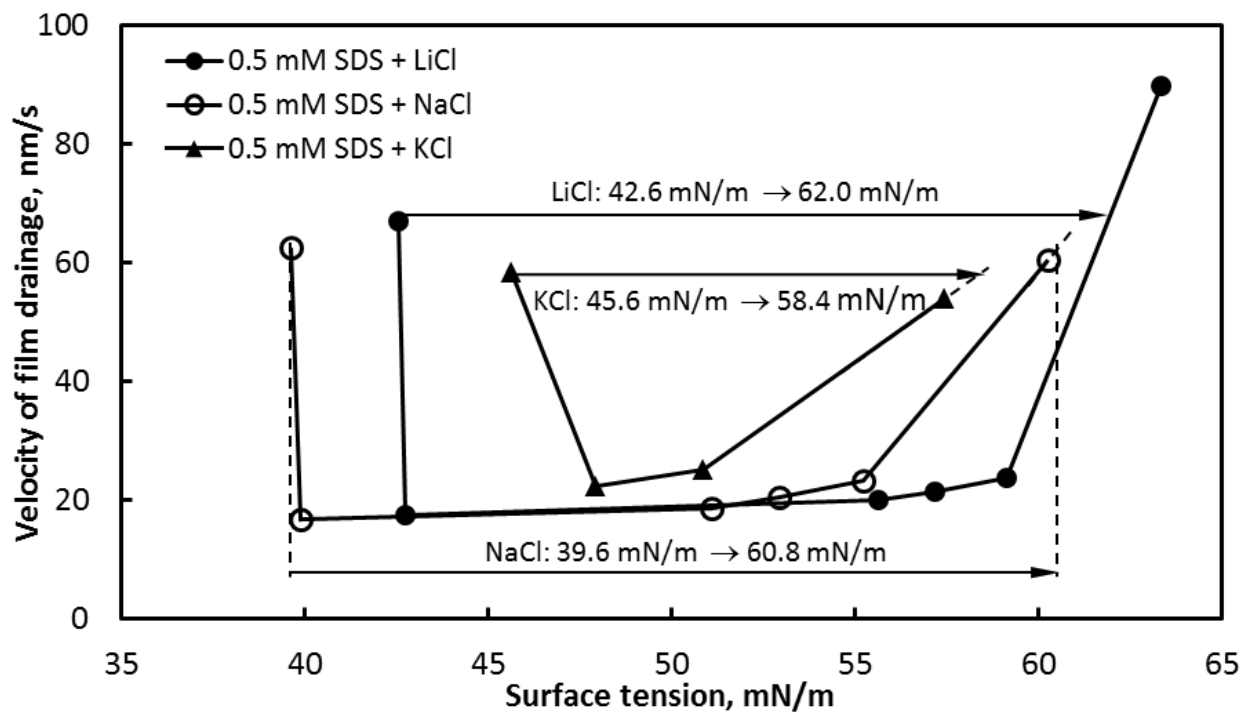

Figure 15. Velocity of film drainage versus surface tension of air/water interface for the three particular cases $-0.5 \mathrm{mM} \mathrm{SDS}+\mathrm{LiCl}, 0.5 \mathrm{mM} \mathrm{SDS}+\mathrm{NaCl}$, and 0.5 mM SDS + KCl.

This unexpected increase of the speed of film drainage ${ }_{2}$ eorrespends-in our opinion, corresponds to the increased value of the surface tension related to the decrease of adsorption of $\mathrm{DS}^{-}$ions on the film's surfaces. The transitions from lower equilibrium to the higher dynamic values of the surface tension are indicated in Fig. 15 with horizontal arrows. One can see that in all of the-cases after the transition, the new values of the-surface tension are in the region of strong dependence of the rate of film drainage on the surface tension. Another possible way to determine the surface tension at the very critical point of destabilization of the foam film is by means of its experimental elasticity. However, this could be possible only if the experimental elasticity coincides with the Gibbs elasticity. It is evident from Tables 2 and 4 the significant difference between the values of the Gibbs and the experimental elasticities.

Another dynamic effect that could affect the drainage of the foams, besides higher surface tension from lower surfactant coverage, is the electrophoretic mobility of the $\mathrm{Li}^{+}, \mathrm{Na}^{+}$, and $\mathrm{K}^{+}$ions[118]. The possible reason for such behavior could be the emergence of streaming potential across the foam film, which polarizes the film[119]. The backward flow of counterions close to the film surfaces reduces the drainage of the foam film. The larger the electrophoretic mobility of the counter-ions, the faster the backward flow at the film surfaces, is, and the-slower the foam film drainage-is. We plotted the speed of drainage of the foam film at/after the critical point vs. the electrophoretic mobility of the counter-ions (Fig. 16). Those 
values were measured for salts other than SDS. Wu et al [118]show that the values for the same counterion can be different for different salts. ( e.g $\mathrm{K}+$ has different $\mathrm{EPM}$ in $\mathrm{KCl}$ and in $\mathrm{K}_{3} \mathrm{Fe}(\mathrm{CN})_{6}$. The authors have used the value for $\mathrm{KCl}$. Therefore, these values are not constant and would have been different in SDS.

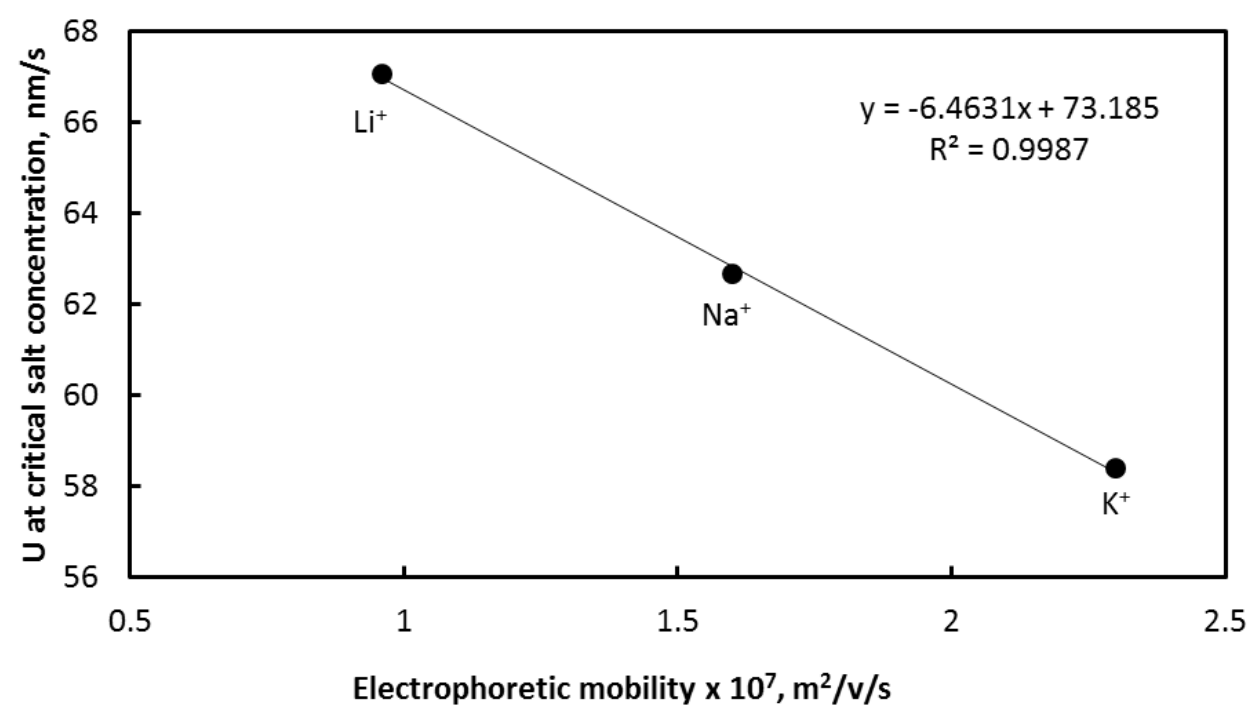

Figure 16. Velocity of drainage of the foam films at the critical point versus the electrophoretic mobility of $\mathrm{Li}^{+}, \mathrm{Na}^{+}, \mathrm{K}^{+}$ions, with Cl- counterion[118] (\& cite $\mathrm{Wu}, 117$ ?).

Yet, one can see a linear dependence $\left(\mathrm{R}^{2}=0.9987\right)$ between the speed of the foam film drainage at the critical point and the electrophoretic mobility of the counter-ions in Fig. 16. As expected, the ions with larger electrophoretic mobility contribute forto slower foam film drainage and vice versa. This is another surprising example of the ion-specificity. The magnitude of the effect, however, is insufficient to explain the sudden increase of speed-of film drainage. The main reason, we believe, is a process similar to the one illustrated in Fig. 17. It should be emphasized that in Fig. 17 we draw only one type of counter-ions (the added ones). This is done because the minimal ratio between the natural counter-ions and the added ones is 1:22 (e.g. in the case of $0.5 \mathrm{mM} \mathrm{SDS}+11 \mathrm{mM}$ added salt). For the case of $45 \mathrm{mM}$ added salt the ratio is even lower, 1:90. Hence, the picture of Fig. 17 is very probable. 


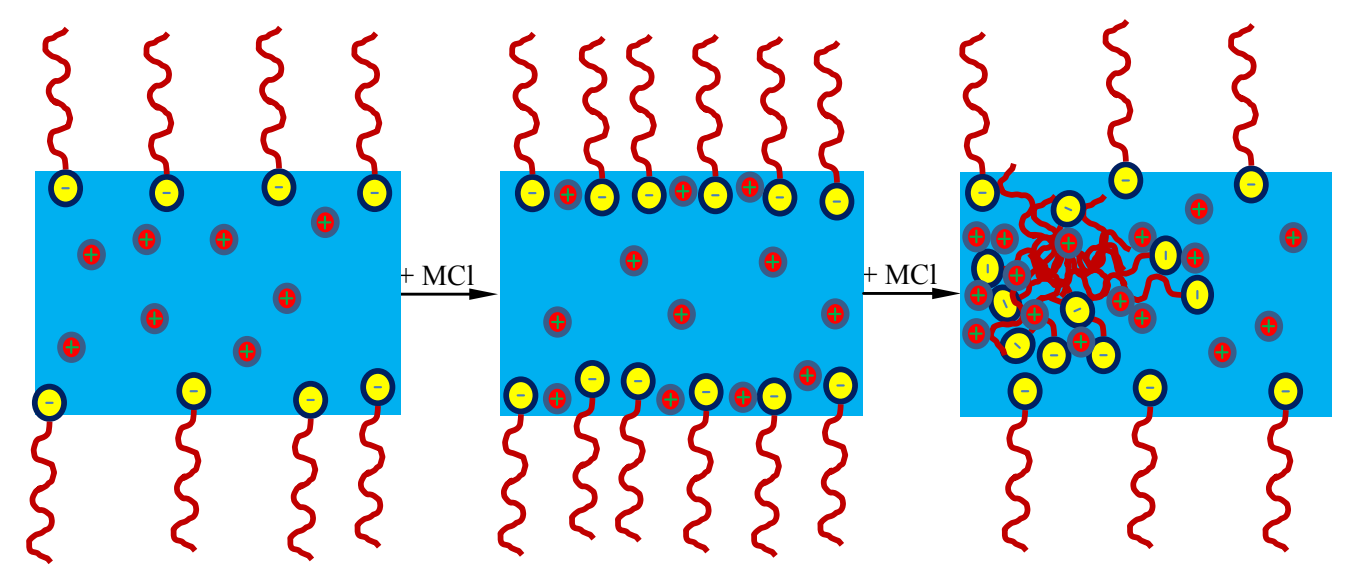

Figure 17. Organization of the surfactant adsorption layer at the air/water interface in the presence of different amounts of added salt $\mathrm{MCl}(\mathrm{M}=\mathrm{Li}, \mathrm{Na}, \mathrm{K})$. a) Partial surface coverage due to electrostatic repulsion between surfactant charged head groups. b) Higher and full coverage of the surface with surfactant molecules, due to the salt screening of the electrostatic charges. c) Incomplete surface coverage, again, due to surfactant precipitation/aggregation at high salt concentrations, and depletion from the film surface.

The physical reason for the sudden transition from stable to unstable foam films at the specific salt concentrations could be sought in the formation of surfactant aggregates (premicelles, see Fig. 17). The formation of pre-micelles at surfactant concentrations significantly below CMC and in the presence of added salt is a known phenomenon in the literature[118]. These nano-aggregates could cause much slower adsorption on the film surfaces, compared to the single surfactant monomers. Though the bulk diffusion coefficient of such nano-structures is smaller by an order of magnitude[120] compared to that of the monomers, ithat is not enough to explain the surface depletion at the observed timescales. In the case of salt concentration below the critical value, the surfactant adsorption layers on film surfaces achieve equilibrium within the order of $10^{-3} \mathrm{~s}[121]$. The kinetics of dissociation of the premicelles is the likely reason for the slow equilibration. The relation between the velocity $V$ of film thinning and the surface elasticity $\varepsilon$ can be expressed by the following equation:

$$
V=\frac{\rho h_{0}\left(g h_{0}\right)^{\frac{3}{2}}}{\varepsilon}
$$

Where $\rho$ is density of water, $h_{0}$ is film thickness, qt which the measurement has begun, and $g$ is acceleration due to gravity. The significant increase of the velocity of film thinning at and beyond the critical salt concentration is likely related to a significant decrease of the value of the surface elasticity, as seen in Eq. (15). The latter is related to the reorganization of the surfactant adsorption layer and the level of the surfactant adsorption. Fig. 17 illustrates the 
process where the addition of salt makes the surfactant adsorption layer denser, however, above a certain critical salt concentration pre-micelles are formed, lowering the effective concentration and disrupting the surfactant packing at the surface adsorption layer. The latter decreases the effect of Marangoni flows, thus causing an increase of the surface mobility and destabilizes the film.

The reason for the difference in surface tension reported in Fig. 15 and the effective tension observed in the film drainage is that the reported surface tension in Fig. 15 was measured under equilibrium conditions in the Scheludko-Exerowa cell. The difference is not surprising because the foam film in the Scheludko-Exerowa cell is formed from doubleconcave droplet, which has been preliminary kept at constant temperature for at least $30 \mathrm{~min}$, which is enough time for achievement of equilibrium of the surfactant adsorption layers. In the case of vertical foam films, the film surfaces are not preliminary equilibrated. Hence, if surfactant adsorption is not fast enough to achieve equilibrium, very fast foam film drainage is expected. It should be emphasized that the latter is not compulsory and depends on the characteristic adsorption time. If the latter is up to 1-2 s, the film drainage experiment is also close to equilibrium. Note also, that film drainage in the Scheludko-Exerowa cell and in the gravitational drainage experiments introduced in ref[114] are driven by different forces, and a direct comparison of the drainage rates should be done with caution. A better way to compare these two different types of drainage experiments is by measuring surface elasticity values, as was done in ref [114], where a reasonable agreement between the results of different experiments was demonstrated.

We have clearly shown that $\mathrm{LiCl}, \mathrm{NaCl}$, and $\mathrm{KCl}$ can either stabilize or de-stabilize the foam films of SDS depending on the salt concentration. The dual effect of added salt $(\mathrm{KCl})$ on the stability of foams has also been observed for systems containing nonionic surfactants, reported in ref[122] .

\subsection{Foam experiments and analysis}

The method of foam generation plays an important role in this process as well. For this Formatted: Indent: Left: 0 " reason a deviation between the critical concentrations in the film and in the foam could be expected. The difference in the critical salt concentrations between foam films and foam could be due to foam fractionation. The large number (and corresponding surface area) of soap bubbles in the foam extracts the surfactant from the bulk solution. For this reason the foam usually has a higher concentration of the surfactant than thatese one of the surfactant solution. ??.Various salt concentrations of $\mathrm{LiCl}, \mathrm{NaCl}$, and $\mathrm{KCl}$ were used with $0.5 \mathrm{mM}$ SDS for the foam column experiments. The volume of liquid drained from the foam column was 
measured from the height of the drained liquid/foam interface at regular intervals of time. Foam stability can be characterized by the volume of liquid in the foam rendered dimensionless tsing by the total liquid in the foam at the start of the experiment, which is found by measuring the total volume of liquid left in the foam column at the end of the experiment after drainage stops. We established that the foam stability correlates very well with the rate of foam drainage. Unstable foam usually drains faster. Fig. 18 presents the volume of liquid drained (Fig. 18A) and the drainage curve (Fig. 18B) of foam prepared from $0.5 \mathrm{mM}$ SDS and added $\mathrm{KCl}$ in the concentration range of $10 \mathrm{mM}-45 \mathrm{mM}$ added salt. One can see that the rate of foam drainage decreases (foam stability enhances) upon the increase of the concentration of $\mathrm{KCl}$ until $45 \mathrm{mM}$, at which the rate of foam drainage is increased substantially. The latter corresponds to low foam stability.
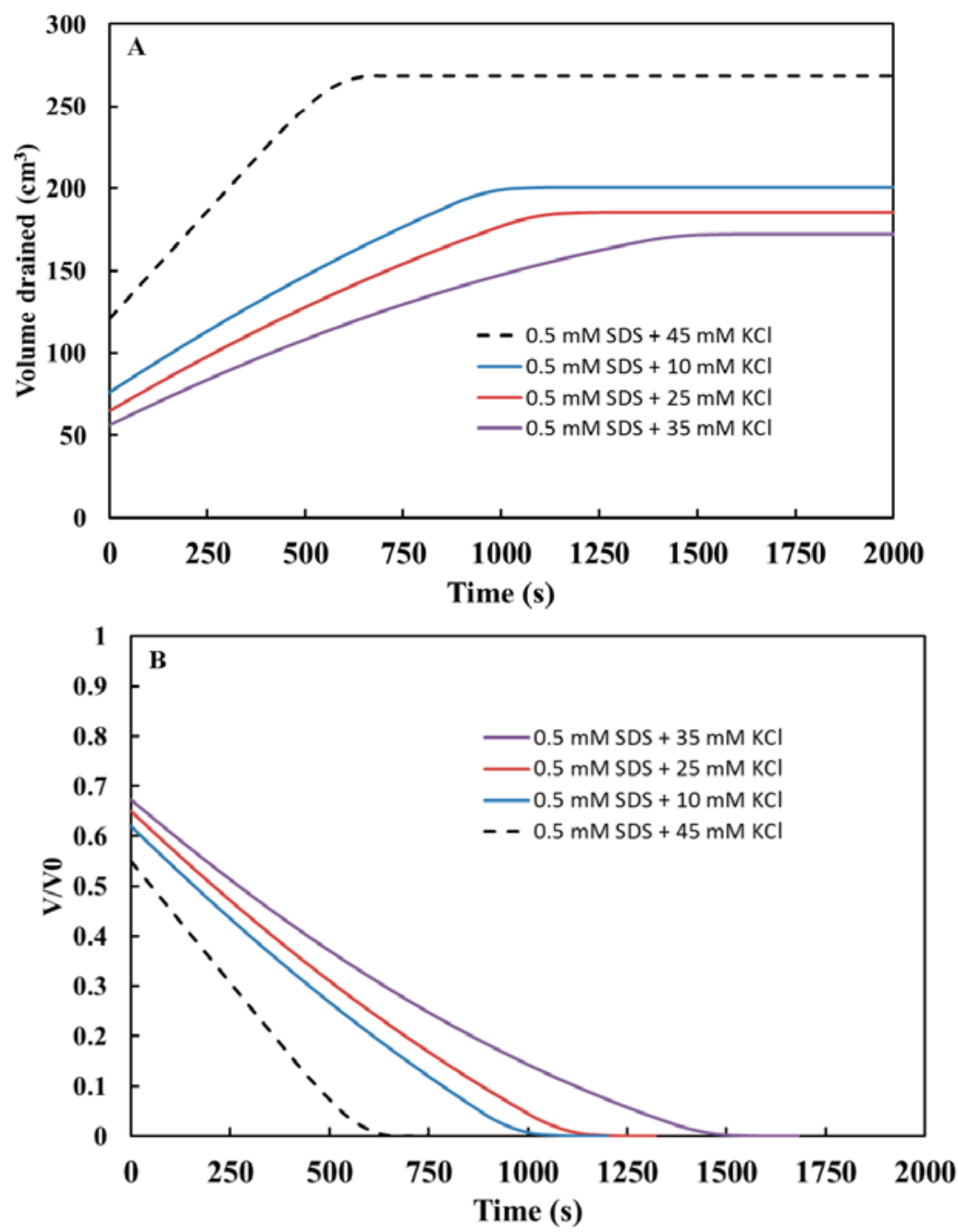
Figure 18. (A) Volume of liquid drained for the first $2000 \mathrm{~s}$ and (B) drainage curves for 0.5 $\mathrm{mM} \mathrm{SDS}+10 \mathrm{mM} \mathrm{KCl}, 25 \mathrm{mM} \mathrm{KCl}, 35 \mathrm{mM} \mathrm{KCl}$ and $45 \mathrm{mM} \mathrm{KCl}$.

One can see that the critical concentration of $\mathrm{KCl}$, at which the foam stability decreases significantly, coincides with this one for foam films $(45 \mathrm{mM} \mathrm{KCl})$. For $\mathrm{LiCl}$ and $\mathrm{NaCl}$ the same trends were observed (Figs. 16S and 16S) but the critical concentrations at which destabilization was observed were twice as high as for the single film experiments. Since the foam geometry depends more significantly on the preparation method, the single film experimental results allow the best analysis for interpretation and prediction. Though not as quantitatively understood, we provide the results of the foam experiments as a reminder of more complex effects due to surfactant fractionation and a practical guide to expectations in foam formulation experiments.

\section{CONCLUSION}

S

This work has the following basic observations:

1. The stability of foams and foam films increases with small amounts of added salt, and the increase can be quantified by the specific energy of counter-ion adsorption at the air/water interface.

2. There is a critical concentration for each salt, above which the salt acts as a defoamer. This can be explained by a reduced solubility (and/or formation of pre-micellar structures) of the surfactant at the critical salt concentration. The critical point of transition to unstable foam films appears at a certain critical value of the adsorption of dodecyl sulfate ions $\left(4.4 \times 10^{-6} \mathrm{~mol} / \mathrm{m}^{2}\right)$, which does not depend on the type of the salt. The level of this instability, however, depends on the type of the salt.

3. The rate of drainage of the foam film at the salt critical concentration correlates very well with the electrophoretic mobilities of the counter-ions $(\mathrm{Li}+, \mathrm{Na}+, \mathrm{K}+)$; the latter might involve effects of streaming potential along the foam film on velocity of film drainage. 


\section{ASSOCIATED CONTENT}

\section{Supporting Information}

The supporting information includes experimental results of drainage of planar films and foam column, variation of surface tension with specific energy of counter-ion adsorption, velocity of film drainage and surfactant adsorption on the interface.

\section{ACKNOWLEDGMENT}

We thank for financial support the European research council (ERC) grant EMATTER (\#280078) to S.S., as well as COST action "Smart and Green Interfaces" (MP1106) for STSM funding. Stoyan Karakashev thanks the Bulgarian National Science Fund Grant DDVU 02/54 and FP7 project Beyond Everest. We thank Prof. I.B. Ivanov for the kindly supplied data of the surface tension measurements and the-for fruitful discussions.

\section{REFERENCES}

[[1] Kunz W, Henle J, Ninham BW. 'Zur Lehre von der Wirkung der Salze' (About the science of the effect of salts): Franz Hofmeister's historical papers. Current Opinion in Colloid \& Interface Science. 2004;9:19-37.

[2] Poiseuille JL. Sur le mouvement des liquides de nature différente dans les tubes de très petits diamètres. Ann Chim Phys. 1848;21:76-110.

[3] Ostwald W. Lehrbuch der allgemeinen Chemie1885.

[4] Raoult F-M. By Raoult's method of determining the lowering of the freezing point in very dilute solutions. London: Brown and Morris; 1888.

[5] Long. Wiedemann's Annalen.IX:616.

[6] Pringsheim N. Jahrbücher für wissenschaftliche Botanik. Berlin: Gebrüder Borntraeger; 1884.

[7] Hamburger HJ. Ueber den Einfluss chemischer Verbindungen auf Blutkörperchen im Zusammenhang mit ihren Molecular-Gewichten. Archiv für Physiologie. 1886:486-7.

[8] Lewith S. The behaviour of the proteins in the blood serum in the presence of salts. Archiv fuer experimentelle Pathologie und Pharmakologie. 1887;XXIX:1-16.

[9] Hofmeister F. About regularities in the protein precipitating effects of salts and the relation of these effects with the physiological behaviour of salts. Archiv fuer experimentelle Pathologie und Pharmakologie. 1887; XXIV:247-60.

[10] Hofmeister F. About the water withdrawing effect of the salts. Archiv fuer experimentelle Pathologie und Pharmakologie. 1888;XXV:1-30.

[11] Limbeck Rv. About the diuretic effect of salts. Archiv fuer experimentelle Pathologie und Pharmakologie. 1888;XXV:69-86.

[12] Hofmeister F. Investigations about the swelling process. Archiv fuer experimentelle Pathologie und Pharmakologie. 1890;XVII:395-413.

[13] Hofmeister F. The contribution of dissolved components to swelling processes. Archiv fuer experimentelle Pathologie und Pharmakologie. 1891;XXVIII:210-38.

[14] Muenzer E. The general effect of salts. Archiv fuer experimentelle Pathologie und Pharmakologie. 1898;XLI:74-96. 
[15] Finet S, Skouri-Panet F, Casselyn M, Bonnete F, Tardieu A. The Hofmeister effect as seen by SAXS in protein solutions. Curr Opin Colloid Interface Sci. 2004;9:112-6.

[16] Bostrom M, Williams DRM, Ninham BW. Why the properties of proteins in salt solutions follow a Hofmeister series. Curr Opin Colloid Interface Sci. 2004;9:48-52.

[17] Leontidis E. Hofmeister anion effects on surfactant self-assembly and the formation of mesoporous solids. Curr Opin Colloid Interface Sci. 2002;7:81-91.

[18] Bauduin P, Renoncourt A, Touraud D, Kunz W, Ninham BW. Hofmeister effect on enzymatic catalysis and colloidal structures. Current Opinion in Colloid \& Interface Science. 2004;9:43-7.

[19] Kunz W, Lo Nostro P, Ninham BW. The present state of affairs with Hofmeister effects. Curr Opin Colloid Interface Sci. 2004;9:1-18.

[20] Kunz W. Specific ion effects in colloidal and biological systems. Curr Opin Colloid Interface Sci. 2010;15:34-9.

[21] Ivanov IB, Slavchov RI, Basheva ES, Sidzhakova D, Karakashev SI. Hofmeister Effect on Micellization, Thin Films and Emulsion Stability Adv Colloid Interface Sci. 2011;168:93-104.

[22] Setschenow J. Über Die konstitution der salzlösungen auf Grund ihres verhaltens zu Kohlensäure. Z Physik Chem 1889;4.

[23] Gorgenyi M, Dewulf J, Van Langenhove H, Heberger K. Aqueous salting-out effect of inorganic cations and anions on non-electrolytes. Chemosphere. 2006;65:802-10.

[24] Heydweiller A. Concerning the physical characteristics of solutions in correlation. II. Surface tension and elcetronic conductivity of watery salt solutions. Annalen Der Physik. 1910;33:145-85.

[25] Langmuir I. The Constitution and Fundamental Properties of Solids and Liquids. II. Liquids. J Am Chem Soc. 1917;39:1848-906.

[26] Wagner C. The surface tension of dilute solutions of electrolytes. Phys Z. 1924;25:474.

[27] Onsager L, Samaras NNT. The surface tension of Debye-Huckel electrolytes. Journal of Chemical Physics. 1934;2:528-36.

[28] Jones G, Ray WA. Surface tension of solutions. Journal of the American Chemical Society. $1935 ; 57: 957-8$.

[29] Jones G, Ray WA. Surface tension of solutions of electrolytes as a function of the concentration. I. A differential method for measuring relative surface tensions. J Am Chem Soc. 1937;59:187-98.

[30] Jones G, Ray WA. The surface tension of solutions of electrolytes as a function of the concentration. III. Sodium chloride. J Am Chem Soc. 1941;63:3262-3.

[31] Jones G, Ray WA. The surface tension of solutions of electrolytes as a function of the concentration. II. J Am Chem Soc. 1941;63:288-94.

[32] Jones G, Ray WA. The surface tension of solutions of electrolytes as a function of the concentration. IV. Magnesium sulfate. J Am Chem Soc. 1942;64:2744-5.

[33] Dole M. A theory of surface tension of aqueous solutions. JACS. 1938;60:904-11.

[34] Dole M, Swartout JA. A twin-ring surface tensiometer. I. The apparent surface tension of potassium chloride solutions. JACS. 1940;62:3039-45.

[35] Randles JEB. Ionic hydration and the surface potential of aqueous electrolytes. Discussions of the Faraday Society. 1957;No. 24:194-9.

[36] Jarvis NL, Scheiman MA. Surface potentials of aqueous electrolyte solutions. J Phys Chem. 1968;72:74-8.

[37] Bhuiyan LB, Bratko D, Outhwaite CW. Electrolyte surface tension in the modified PoissonBoltzmann approximation. J Phys Chem. 1991;95:336-40.

[38] Weissenborn PK, Pugh RJ. Surface tension of aqueous solutions of electrolytes: relationship with ion hydration, oxygen solubility, and bubble coalescence. J Colloid Interface Sci. 1996;184:550-63.

[39] Bostroem M, Williams DRM, Ninham BW. Surface tension of electrolytes: Specific ion effects explained by dispersion forces. Langmuir. 2001;17:4475-8.

[40] Jungwirth P, Tobias D. Molecular structure of salt solutions: A new view of the interface with implications for heterogeneous atmospheric chemistry. J Phys Chem B. 2001;105:10468.

[41] Markin VS, Volkov AG. Quantitative Theory of Surface Tension and Surface Potential of Aqueous Solutions of Electrolytes. J PhyS Chem B. 2002;106:11810-7.

[42] Bostroem M, Kunz W, Ninham BW. Hofmeister Effects in Surface Tension of Aqueous Electrolyte Solution. Langmuir. 2005;21:2619-23. 
[43] dos Santos AP, Levin Y. Ion Specificity and the Theory of Stability of Colloidal Suspensions. Phys Rev Lett. 2011;106.

[44] Slavchov RI, Novev JK. Surface tension of concentrated electrolyte solutions. J Colloid Interface Sci 2012;387:234-43.

[45] Markovich T, Andelman D, Podgornik R. Surface tension of electrolyte solutions: A selfconsistent theory (Vol 106, 16002, 2014). Epl. 2014;106.

[46] Karakashev S, Tsekov R, Manev E. Adsorption of alkali dodecyl sulfates on air/water surface. Langmuir. 2001;17:5403-5.

[47] Ennis J, Kjellander R, Mitchell DJ. Dressed ion theory for bulk symmetric electrolytes in the restricted primitive model. Journal of Chemical Physics. 1995;102:975-91.

[48] Kjellander R. Modified Debye-Hueckel Approximation with Effective Charges: An Application of Dressed Ion Theory for Electrolyte Solutions. Journal of Physical Chemistry. 1995;99:10392-407.

[49] Sakai M. Physicochemical properties of small bubbles in liquids. Progress in Colloid \& Polymer Science. 1988;77:136-42.

[50] Koelsch P, Viswanath P, Motschmann H, Shapovalov VL, Brezesinski G, Moehwald H, et al Specific ion effects in physicochemical and biological systems: Simulations, theory and experiments. Coll Surf A. 2007;303:110-36.

[51] Tobias DJ, Hemminger JC. Chemistry - Getting specific about specific ion effects. Science. 2008;319:1197-8.

[52] Marrucci G, Nicodemo L. Coalescence of gas bubbles in aqueous solutions of inorganic electrolytes. Chem Eng Sci. 1967;22:1257-65.

[53] Prince MJ, Blanch HW. Transition electrolyte concentrations for bubble coalescence. AIChE J. 1990;36:1425-9.

[54] Craig VSJ, Ninham BW, Pashley RM. Effect of electrolytes on bubble coalescence. Nature (London). 1993;364:317-19.

[55] Craig VSJ, Ninham BW, Pashley RM. The effect of electrolytes on bubble coalescence in water. J Phys Chem. 1993;97:10192-7.

[56] Pashley RM, Craig VSJ. Effects of Electrolytes on Bubble Coalescence. Langmuir. 1997;13:4772-4.

[57] Karakashev SI, Nguyen PT, Tsekov R, Hampton MA, Nguyen AV. Anomalous Ion Effects on Rupture and Lifetime of Aqueous Foam Films Formed from Monovalent Salt Solutions up to Saturation Concentration. Langmuir. 2008;24:11587-91.

[58] Marrucci G. Theory of coalescence. Chem Eng Sci. 1969;24:975-85.

[59] Weissenborn PK, Pugh RJ. Coalescence of bubbles in aqueous solutions of electrolytes. Proc Int Miner Process Congr, 19th. 1995;3:125-8.

[60] Weissenborn PK, Pugh RJ. Surface Tension and Bubble Coalescence Phenomena of Aqueous Solutions of Electrolytes. Langmuir. 1995;11:1422-6.

[61] Marcelja S. Selective Coalescence of Bubbles in Simple Electrolytes. J Phys Chem B. 2006;110:13062-7.

[62] Pitzer KS. Thermodynamics of electrolytes. I. Theoretical basis and general equations. Journal of Physical Chemistry. 1973;77:268-77.

[63] Pitzer KS, Mayorga G. Thermodynamics of electrolytes. II. Activity and osmotic coefficients for strong electrolytes with one or both ions univalent. Journal of Physical Chemistry. 1973;77:2300-8.

[64] Pitzer KS, Mayorga G. Thermodynamics of electrolytes. III. Activity and osmotic coefficients for 2-2 electrolytes. Journal of Solution Chemistry. 1974;3:539-46.

[65] Pitzer KS, Kim JJ. Thermodynamics of electrolytes. IV. Activity and osmotic coefficients for mixed electrolytes. Journal of the American Chemical Society. 1974;96:5701-7.

[66] Adam NK, Shute HL. Anomalies in the surface tension of paraffin chain salts. Trans Faraday Soc. 1938;34:758-65.

[67] Pethica BA. The adsorption of surface active electrolytes at the air/water interface. Trans Faraday Soc. 1954;50:413-21.

[68] Matijevic E, Rogers J. Surface Properties of Sodium Octyl Sulphate in Saturated Salt Solutions. Nature. 1957;180:560-1.

[69] van Voorst Vader F. Adsorption of detergents at the liquid-liquid interface. I. Trans Faraday Soc. 1960;56:1067-77. 
[70] Davies JT, Rideal EK. Interfacial Phenomena, 2nd ed. New York: Academic Press; 1963.

[71] Weil I. Surface Concentration and the Gibbs Adsorption Law. The Effect of the Alkali Metal Cations on Surface Behavior1. J Phys Chem. 1966;70:133-40.

[72] Lucassen-Reynders EH. Surface equation of state for ionized surfactants. J Phys Chem. 1966;70:1777-85.

[73] Tajima K. Radiotracer studies on adsorption of surface-active substance at aqueous surface. II. Effect of excess salt on the adsorption of sodium dodecyl sulfate. Bull Chem Soc Jpn. 1970;43:3063-6.

[74] Motomura K. Thermodynamic studies on adsorption at interfaces. I. General formulation. J Colloid Interface Sci. 1978;64:348-55.

[75] Lucassen-Reynders EH. Anionic Surfactants. New York: Marcel Dekker; 1981.

[76] Borwankar RP, Wasan DT. The effect of surfactants on interphase solute transport. A theory of interfacial resistance. Industrial \& Engineering Chemistry Fundamentals. 1986;25:662-8.

[77] Kralchevsky PA, Danov KD, Broze G, Mehreteab A. Thermodynamics of Ionic Surfactant Adsorption with Account for the Counterion Binding: Effect of Salts of Various Valency. Langmuir. 1999; 15:2351-65.

[78] Ivanov IB, Ananthapadmanabhan KP, Lips A. Adsorption and structure of the adsorbed layer of ionic surfactants. Adv Colloid Interface Sci. 2006;123-126:189-212.

[79] Slavchov RI, Karakashev SI, Ivanov IB. Ionic Surfactants and Ion-Specific Effects: Adsorption, Micellization, Thin Liquid Films. In: Romsted LS, (editor). Surfactant Science and Technology: Retrospects and Prospects: Taylor \& Francis Group; 2014. p. 593.

[80] Lu JR, Marrocco A, Su T, Thomas RK, Penfold J. Adsorption of dodecyl sulfate surfactants with monovalent metal counterions at the air-water interface studied by neutron reflection and surface tension. J Colloid Interface Sci. 1993;158:303-16.

[81] Borwankar RP, Wasan DT. Equilibrium and dynamics of adsorption of surfactants at fluid-fluid interfaces. Chem Eng Sci. 1988;43:1323-37.

[82] Manev ED, Sazdanova SV, Tsekov R, Karakashev SI, Nguyen AV. Adsorption of ionic surfactants. Coll Surf A. 2008;319:29-33.

[83] Fainerman VB, Miller R, Mohwald H. General relationships of the adsorption behavior of surfactants at the water/air interface. J Phys Chem B. 2002;106:809-19.

[84] Koelsch P, Motschmann H. An experimental route to Hofmeister. Curr Opin Colloid Interface Sci. 2004;9:87-91.

[85] Li HH, Imai Y, Yamanaka M, Hayami Y, Takiue T, Matsubara H, et al. Specific counterion effect on the adsorbed film of cationic surfactant mixtures at the air/water interface. J Colloid Interface Sci. 2011;359:189-93.

[86] Ladanyi BM. Computer simulation studies of counterion effects on the properties of surfactant systems. Curr Opin Colloid Interface Sci. 2013;18:15-25.

[87] Marcus Y. Ion properties. New York: Marcel Dekker; 1997.

[88] Ivanov IB, Marinova KG, Danov KD, Dimitrova D, Ananthapadmanabhan KP, Lips A. Role of the counterions on the adsorption of ionic surfactants. Adv Colloid Interface Sci. 2007;134-135:10524.

[89] Karakashev SI, Smoukov SK. Fast estimation of the equilibrium adsorption constants of ionic surfactants with account for ion-specific effects. Coll Surf A. 2015;467:143-8.

[90] Karakashev SI. How to determine the adsorption energy of the surfactant's hydrophilic head? How to estimate easily the surface activity of every simple surfactant? J Colloid Interface Sci. 2014;432:98-104.

[91]

[92] Exerowa D, Kruglyakov PM. Foam and Foam Films: Theory, Experiment, Application. New York, NY: Marcel Dekker; 1997.

[93] Weaire D, Hutzler S. Physics of Foams: Oxford University Press; 1999.

[94] Pugh RJ. Foams and foaming. Handbook of Applied Surface and Colloid Chemistry. 2002;2:2343.

[95] Karakashev SI, Georgiev P, Balashev K. Foam production - ratio between foaminess and rate of foam decay. J Colloid Interface Sci. 2012;379:144-7.

[96] Li XL, Shaw R, Stevenson P. Effect of humidity on dynamic foam stability. Int J Miner Process. 2010;94:14-9. 
[97] Li X, Karakashev SI, Evans GM, Stevenson P. Effect of Environmental Humidity on Static Foam Stability. Langmuir. 2012;28:4060-8.

[98] Johansson G, Pugh RJ. The influence of particle size and hydrophobicity on the stability of mineralized froths. Int J Miner Process. 1992;34:1-21.

[99] Alargova RG, Warhadpande DS, Paunov VN, Velev OD. Foam superstabilization by polymer microrods. Langmuir. 2004;20:10371-4.

[100] Kruglyakov PM, Elaneva SI, Vilkova NG. About mechanism of foam stabilization by solid particles. Adv Colloid Interface Sci. 2011;165:108-16.

[101] Karakashev SI, Manev ED. Correlation in the properties of aqueous single films and foam containing a nonionic surfactant and organic/inorganic electrolytes. J Colloid Interface Sci. 2003;259:171-9.

[102] Karakashev SI, Manev ED, Nguyen AV. Effect of Thin Film elasticity on Foam stability. Annuare of Sofia University. 2011;102/103:153-63.

[103] Manev ED, Nguyen AV. Effects of surfactant adsorption and surface forces on thinning and rupture of foam liquid films. International Journal of Mineral Processing. 2005;77:1-45.

[104] Wantke KD, Fruhner H. The relationship between foam stability and surface rheological properties. Prog Trends Rheol V, Proc Eur Rheol Conf, 5th. 1998:315-6.

[105] Pandey S, Bagwe RP, Shah DO. Effect of counterions on surface and foaming properties of dodecyl sulfate. J Colloid Interface Sci. 2003;267:160-6.

[106] Schelero N, Hedicke G, Linse P, Klitzing RV. Effects of Counterions and Co-ions on Foam Films Stabilized by Anionic Dodecyl Sulfate. J Phys Chem B. 2010;114:15523-9.

[107] Pugh RJ, Manev ED. Froth Stability in Aqueous-Solutions of Nonionic Surfactant and Inorganic Electrolyte. J Colloid Interface Sci. 1992;152:582-4.

[108] Manev ED, Pugh RJ. Diffuse layer electrostatic potential and stability of thin aqueous films containing a nonionic surfactant. Langmuir. 1991;7:2253-60.

[109] Qu X, Wang LG, Karakashev SI, Nguyen AV. Anomalous thickness variation of the foam films stabilized by weak non-ionic surfactants. J Colloid Interface Sci. 2009;337:538-47.

[110] Wang LQ, Yoon RH. Role of hydrophobic force in the thinning of foam films containing a nonionic surfactant. Coll Surf A. 2006;282:84-91.

[111] Jungwirth P, Tobias DJ. Specific ion effects at the air/water interface. Chemical Reviews. 2006;106:1259-81.

[112] Jungwirth P, Tobias DJ. Ions at the air/water interface. J Phys Chem B. 2002;106:6361-73.

[113] Slavchov RI, Ivanov TI. Quadrupole terms in the Maxwell equations: Born energy, partial molar volume, and entropy of ions. J Chem Phys. 2014;140.

[114] Sett S, Sinha-Ray S, Yarin AL. Gravitational Drainage of Foam Films. Langmuir. 2013;29:4934-47.

[115] Jun S, Pelot DD, Yarin AL. Foam Consolidation and Drainage. Langmuir. 2012;28:5323-30.

[116] Helfand E, Frish H, Lebowitz J. Theory of the Two- and One-Dimensional Rigid Sphare Fluids. J Chem Phys. 1961;34:1037-42.

[117] Baxter RJ. Pressure in Percus-Yevick Approximation. J Chem Phys. 1967;47:4855-\&.

[118] Wu J, Gerstandt K, Zhang H, Liu J, Hinds BJ. Electrophoretically induced aqueous flow through single-walled carbon nanotube membranes. Nature Nanotechnology. 2012;7:133-9.

[119] Karakashev SI, Tsekov R. Electro-Marangoni Effect in Thin Liquid Films. Langmuir. 2011;27:265-70.

[120] Jiang Y, Chen H, Cui X-H, Mao S-Z, Liu M-L, Luo P-Y, et al. H-1 NMR study on premicellization of quaternary ammonium gemini surfactants. Langmuir. 2008;24:3118-21.

[121] Danov KD, Kolev VL, Kralchevsky PA, Broze G, Mehreteab A. Adsorption kinetics of ionic surfactants after a large initial perturbation. Effect of surface elasticity. Langmuir. 2000;16:2942-56.

[122] Pugh RJ, Manev ED. Froth stability in aqueous solutions of nonionic surfactant and inorganic electrolyte. J Colloid Interface Sci. 1992;152:582-4. 